\title{
Peer-To-Peer Support Responses to LGBT Suicidal Ideations in an Online Community
}

\author{
Kayla McCormick
}

Follow this and additional works at: https://researchrepository.wvu.edu/etd

\section{Recommended Citation}

McCormick, Kayla, "Peer-To-Peer Support Responses to LGBT Suicidal Ideations in an Online Community" (2017). Graduate Theses, Dissertations, and Problem Reports. 6193.

https://researchrepository.wvu.edu/etd/6193

This Thesis is protected by copyright and/or related rights. It has been brought to you by the The Research Repository @ WVU with permission from the rights-holder(s). You are free to use this Thesis in any way that is permitted by the copyright and related rights legislation that applies to your use. For other uses you must obtain permission from the rights-holder(s) directly, unless additional rights are indicated by a Creative Commons license in the record and/ or on the work itself. This Thesis has been accepted for inclusion in WVU Graduate Theses, Dissertations, and Problem Reports collection by an authorized administrator of The Research Repository @ WVU. For more information, please contact researchrepository@mail.wvu.edu. 


\title{
Peer-To-Peer Support Responses to LGBT Suicidal Ideations in an Online Community
}

\author{
Kayla McCormick
}

Thesis submitted to the Eberly College of Arts and Sciences at West Virginia University

in partial fulfillment of the requirements for the degree of

Master of Science in Sociology

Karen Weiss, Ph.D., Chair

Melissa Latimer, Ph.D.

Walter DeKeseredy, Ph.D.

Department of Sociology and Anthropology

Morgantown, West Virginia

2017

Keywords: social support, LGBT, LGBTQ, suicide, transgender, online, stress buffering

Copyright 2017: Kayla McCormick 


\title{
ABSTRACT \\ Peer-To-Peer Support Responses to LGBTQ Suicidal Ideations in an Online Community
}

\author{
Kayla McCormick
}

LGBTQ individuals, especially youth, are one of the top groups at risk for suicide. They experience social stigma and discrimination which diminishes their access to common support resources, causing many to turn to online communities for support for common issues. This paper utilizes qualitative content analysis guided by the stress-buffering model of the social support theory to investigate the helpfulness of informal social support responses in buffering stress in the suicidal individuals on LGBTchat.net. This model is based on the buffering hypothesis which asserts that persons with high stress and low support will show disproportionately elevated symptomatology, and that higher levels of support helps to "buffer" stress. Evidence of stress-buffering is based on whether the type of support, or functioning buffer mechanisms, provided by responders matches the helpseeking individuals' needs. There were three categories of needs: emotional need, informational need, and both needs. All 36 sample threads were found to have matched responses, and therefore, overall support provided in this forum for suicidal individuals is evaluated as helpful in buffering stress. Variations within emotional and informational support are discussed. In addition, other themes emerged from the data through the coding and analysis process. These themes included evidence of LGBTchat.net serving as a true community, that forum members have awareness of suicide, mental health, and of the limitations on their ability to offer support through the internet, and that professional resources are limited in providing social support to isolated individuals. Moreover, there were many issues encountered through applying the stress-buffering matching model qualitatively. These issues are discussed in depth and point to the conclusion that human interactions, especially those online, are too complex for such a simple and vague model of analysis to fully encompass. A critique of the stress-buffering model will also be provided. 


\section{Table of Contents}

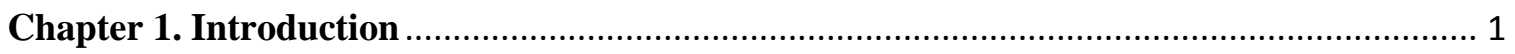

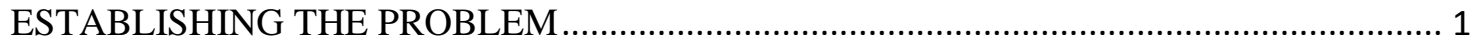

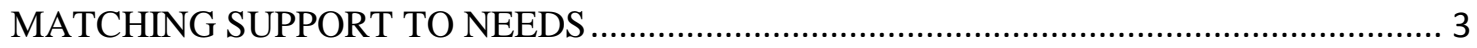

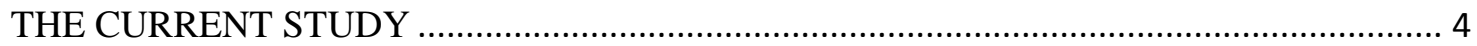

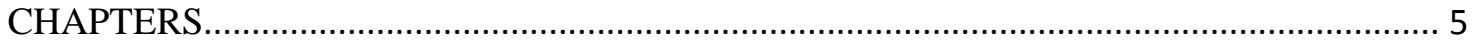

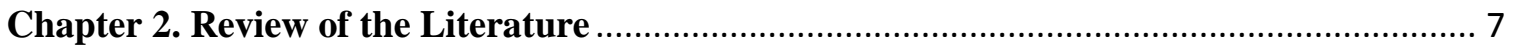

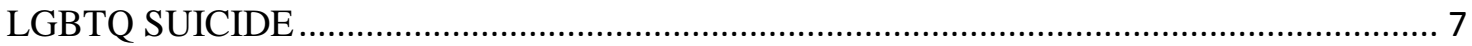

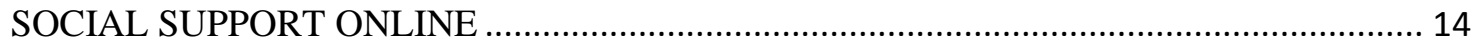

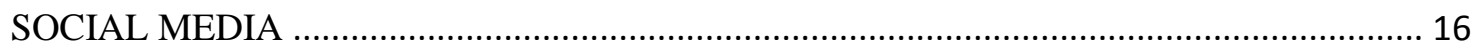

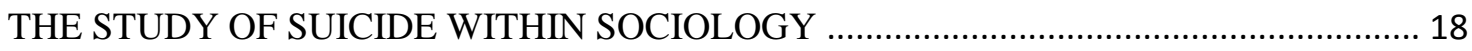

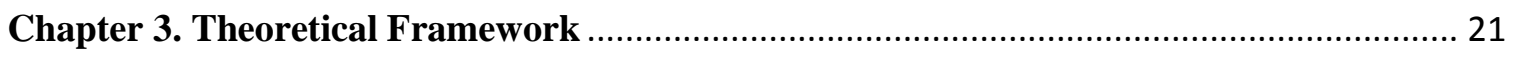

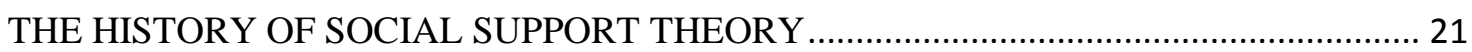

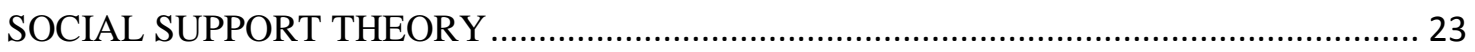

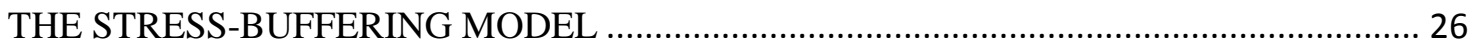

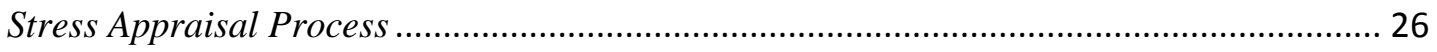

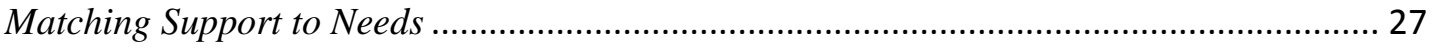

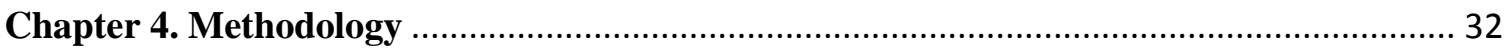

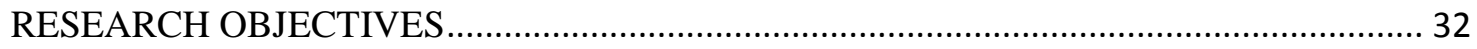

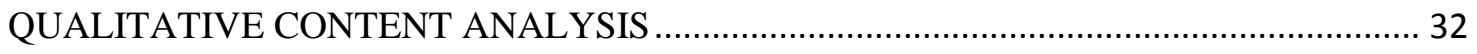

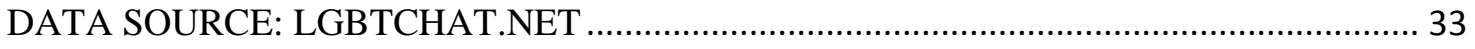

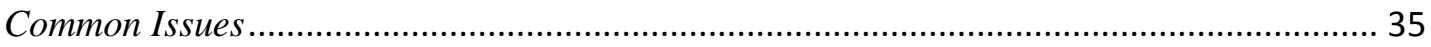

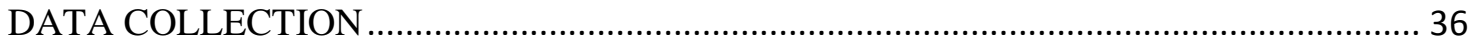

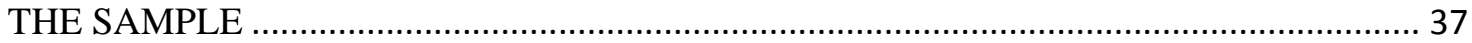

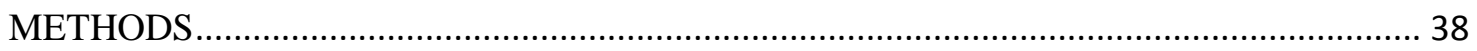

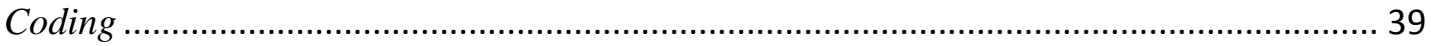

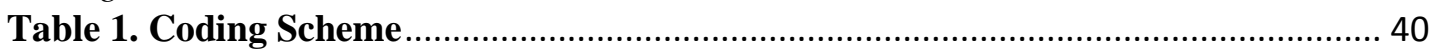

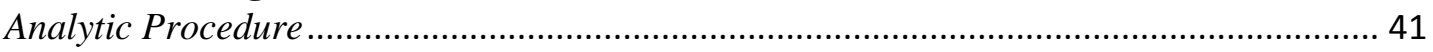

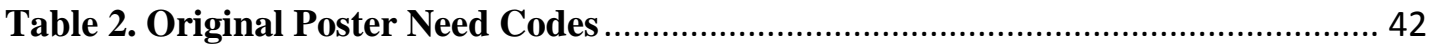

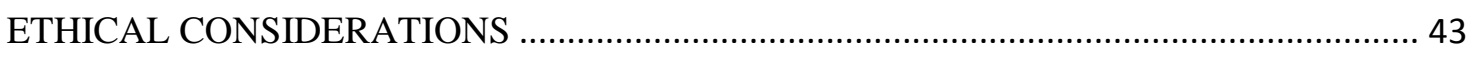

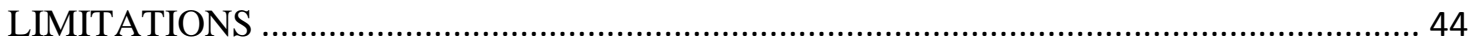

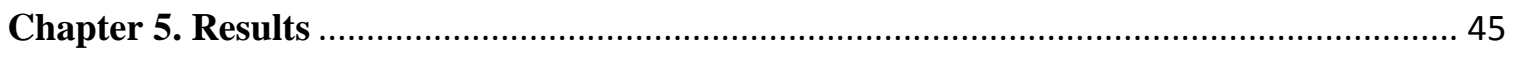

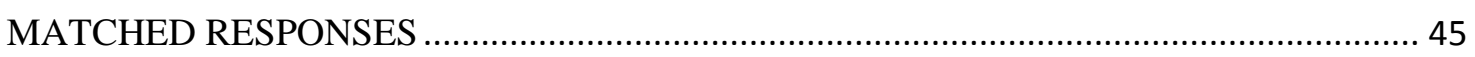

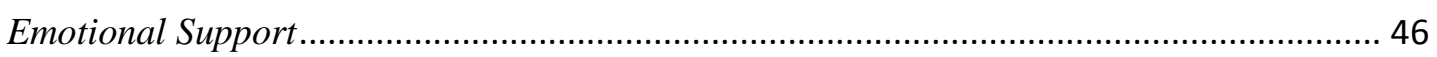

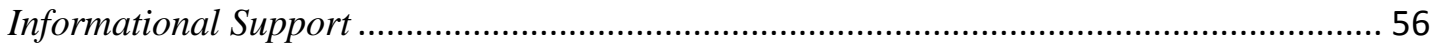

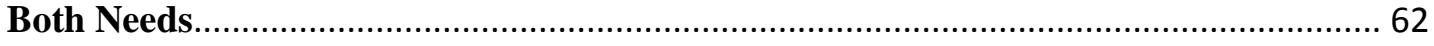

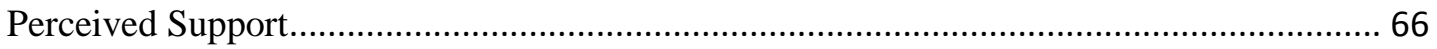




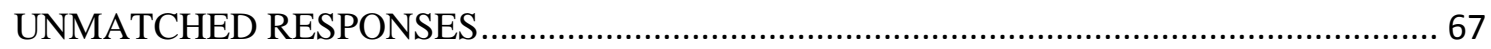

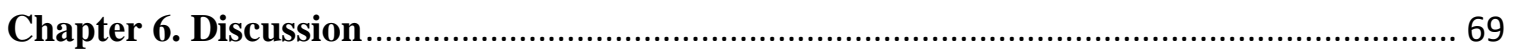

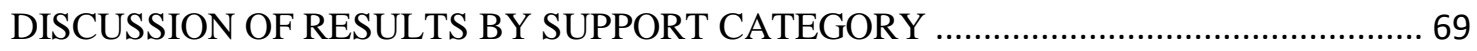

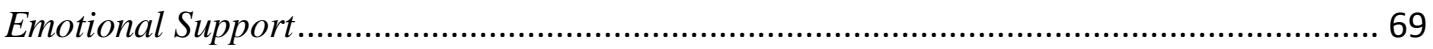

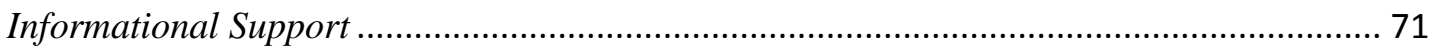

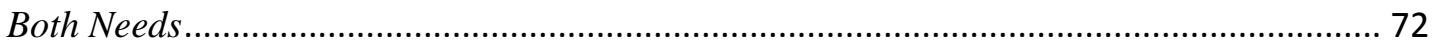

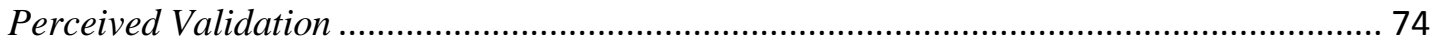

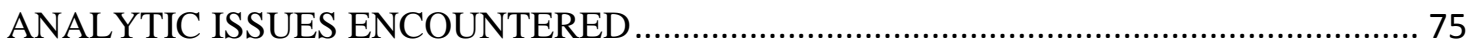

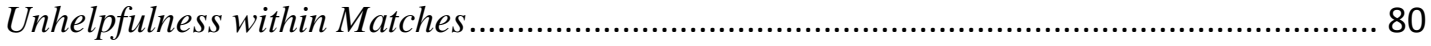

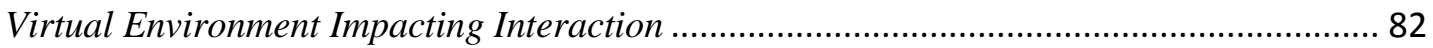

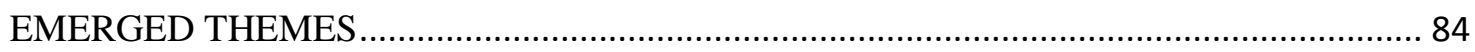

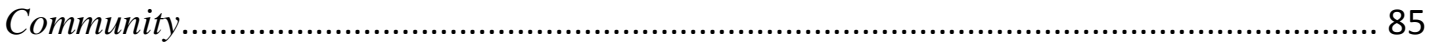

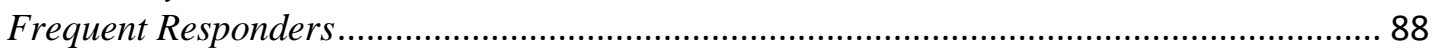

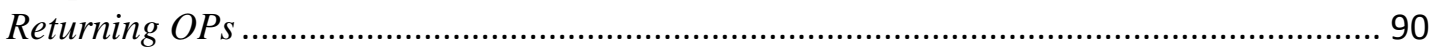

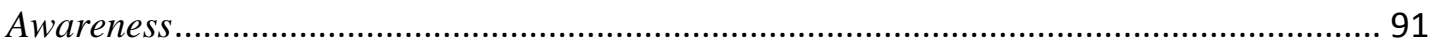

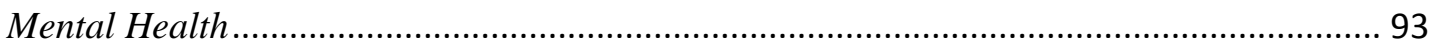

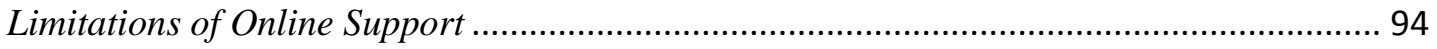

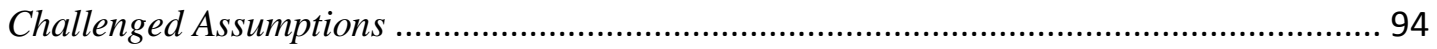

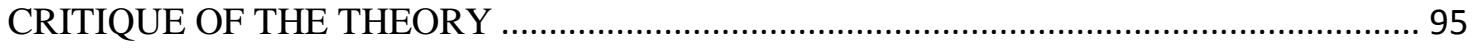

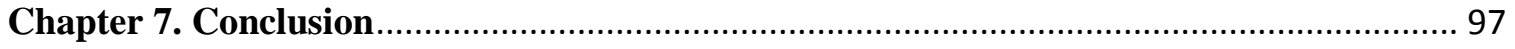

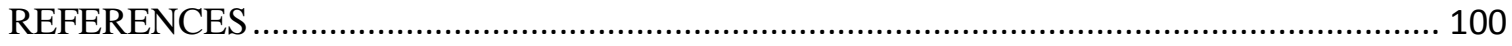




\section{Chapter 1. Introduction}

\section{ESTABLISHING THE PROBLEM}

Annually, over 800,000 people worldwide (1.5\% of all deaths) die from suicide and it was the leading cause of death for people ages 15-29 in 2015 according to the World Health Organization (2016). According to the Centers for Disease Control and Prevention (CDC), 44,193 Americans complete suicide each year and for every completed suicide, there are 25 more attempts (2013). Caring for these individuals costs the United States $\$ 44$ billion annually. Some people are at more elevated risk for suicide than others. LGBTQ ${ }^{1}$ individuals, especially youth, are recognized as being at particularly high risk. These individuals are three to five times more likely to feel suicidal than heterosexual youth (Marshal et al. 2011).

Members of the LGBTQ community are subject to stigma, discrimination, harassment, and assault as a result of the prevalence and acceptance of wider heteronormative ${ }^{2}$ societal attitudes and norms. Discriminatory behaviors occur in all aspects of society, including the family unit, which creates an unwelcoming environment. Many of these individuals risk rejection from their families, homelessness, and/or abuse. Access to social support (such as support from the family or community) is restricted or

\footnotetext{
${ }^{1}$ Collective acronym referring to lesbian, gay, bisexual, transgender, and queer or questioning sexualities or gender identities. The acronym is ever-adapting and expanding to fully represent the spectrum of identities within gender and sexual orientation. LGBTQ is used in this study for simplicity as well as the encompassing use of the $\mathrm{Q}$ to cover other queer identities as an umbrella term.

${ }^{2}$ Defined as "the suite of cultural, legal, and institutional practices that maintain normative assumptions that there are two and only two genders, that gender reflects biological sex, and that only sexual attraction between these "opposite" genders is natural or acceptable (Kitzinger 2005)" (Schilt and Westbrook 2009:441)
} 
nonexistent for many LGBTQ individuals due to the stigma attached to their identities. Additionally, formal support, such as therapy, may also be unattainable for similar reasons. This lack of access to support has caused many LGBTQ individuals to turn to alternate means, such as online support groups. For many at-risk individuals, online forums may be their only outlet for finding social support. This is especially true if they are closeted, or actively concealing their sexuality/gender identity. Therefore, it is imperative to examine the helpfulness and appropriateness of the support responses that these isolated individuals receive.

Despite the role that online communities serve for suicidal help-seekers, such informal support may not be appropriate or safe. Concerns about the appropriateness of support from online peers have been raised by researchers. This study delves into this issue and evaluates the effectiveness of social support responses provided to LGBTQ individuals experiencing suicidal ideations ${ }^{1}$ on LGBTchat.net, a popular online LGBTQspecific chat forum. In this context, ideation can be sparked by a traumatic situation or from enduring chronic negative life experiences and is often linked to mental illness, such as depression. While depression can be treated or tempered with medication, therapy, and healthy lifestyle practices, events in which a person is actively suicidal cannot be treated in the same manner. In these high-risk situations, seeking online help in place of clinical interventions may not be sufficient, or safe.

\footnotetext{
${ }^{1}$ Suicidal ideation means that someone is having suicidal thoughts, ruminations, or preoccupations with contemplating suicide (Silverman 2006).
} 
In an effort to decrease LGBTQ suicidal behaviors and ideation, there has been an increased emphasis on establishing evidence based suicide prevention programs in the U.S. The Substance Abuse and Mental Health Services Administration, a branch of the U.S. Department of Health and Human Services, funds large prevention programs across the country that aim to educate and train the average person on how to mitigate situations involving suicidal individuals. In spite of these efforts, many people are unaware of the proper ways to handle these sensitive situations and struggle to help their loved ones through difficult situations. The support provided to suicidal individuals should be tailored to their specific needs in order to be most effective.

\section{MATCHING SUPPORT TO NEEDS}

Since this at-risk population lacks access to social support, efforts must be taken to ensure these individuals are being reached and treated. To this end, informal sources of support, like online support groups, should be investigated in order to evaluate the adequacy of available support in matching the unique needs of the individuals.

The buffering hypothesis and stress-buffering effect presented by Cohen and McKay (1984) and evaluated by Cohen and Wills (1985) provide the theoretical framework used to guide the methodology and analysis of this study. Specifically, the matching model (Cohen and Wills 1985) based on the stress-buffering effect model is used to evaluate online responses as helpful in buffering stress and avoiding suicidal attempts in help-seekers. The buffering hypothesis holds that persons with high stress and low support will show disproportionately elevated symptomatology (Cohen and Wills 1985). The stress-buffering effect is a quantitative (statistical) measure of the interaction 
between stress and social support. Under these propositions, social support works to "buffer" stress in individuals after a stressful event, or in the anticipation of one. For stress to be buffered effectively, a match must be made between the type of support provided, referred to as functioning buffer mechanisms, and the individual's need. This is the premise of the matching model. Responses are considered helpful if evidence of a buffering effect is found. There are a range of different buffer mechanisms; however, in this study, they are conceptualized into emotional and informational support. Emotional support mechanisms function to meet one's basic socio-emotional needs and informational support mechanisms add to one's knowledge base.

\section{THE CURRENT STUDY}

The stress buffering effect (developed as a statistical measure) has not previously been applied to discrete and qualitative observations of social support interactions. Following the suggestions of previous research, the current study applies the stress buffering effect in a qualitative manner to evaluate social support responses to online help-seeking behavior. Qualitative content analysis, specifically, is utilized to test the buffering hypothesis. The results of this theoretically framed analysis found that every sample thread was matched with appropriate forms of support, meaning that there is evidence of stress-buffering occurring. This finding suggests that suicidal LGBTQ individuals are finding the social support that they need on LGBTchat.net, that suicide attempts are avoided, and that this online forum holds potential for further individuals to safely seek support. 
In addition to this positive conclusion, other interesting themes emerged from the data. These themes include evidence of LGBTchat.net having characteristics of a true community, that forum users have awareness of suicide, mental health, and the limitations to the support they can provide through the internet, and that professional resources were not sufficient on their own in helping some individuals. This indicates how important the role social support and a sense of belonging is for mental health as well as the potential for online support groups to fill this role for isolated individuals.

Online responders rely on the way in which the original posters (OPs) communicate their needs through their disclosing posts in order to effectively respond. This resulted in a variation in the responses provided, as some OPs were more efficient at directly communicating their needs. As a result, the matching model of analysis was insufficient in fully representing the range of social support interactions present within the threads. There were many issues encountered with applying this matching model qualitatively. These issues are presented and discussed in this paper and a critique of the model is provided in order to give directions for future research.

\section{CHAPTERS}

This paper is divided into multiple chapters in order to clearly illustrate the concepts involved. Chapter 2 will provide an overview of relevant literature and statistical research to frame the reasons suicidal LGBTQ individuals seek support online. Chapter 3 serves as the theoretical framework, providing a brief review of social support literature, an in-depth explanation of the social support theory and its two models, as well as how it applies to the phenomena of interest. Chapter 4 explains the methodology for 
data collection, coding, and analysis, describes the data source, and discusses definitions of the buffer mechanism coding scheme. Ethical considerations and study limitations are also presented in this chapter. Chapter 5 presents the results of this investigation and provides examples of matched threads. Chapter 6 serves as the discussion, examining the implications and interpretations of the data. This includes identifying and describing patterns found in the matching data, as well as unforeseen results and their implications for the concluding analysis. Lastly, this chapter includes a critique of the stress buffering model. The last chapter (chapter 7) provides a conclusion for this research including implications of the analysis, as well as directions for future research. 


\section{Chapter 2. Review of the Literature}

This chapter provides an overview of the existing research on how suicide impacts the LGBTQ community and the unique experiences and factors facing this population that lead to disproportionately high rates of suicidal behaviors. The LGBTQ community is tremendously understudied in the literature areas of suicidal behaviors and social support, especially because surveys of social support and research of life events that lead to suicide have not included this population. A summary of online social support literature is also provided followed by a discussion on social media and the enticing facets that draw marginalized populations to it as a source through which to seek social support. Last discussed is a summary of sociological research on suicide in order to provide a context and segue into the theoretical framework in the next chapter.

\section{LGBTQ SUICIDE}

Those who identify as a sexual minority are at greater risk for suicidal behavior (both ideation and attempts) than heterosexuals (Blosnich et al. 2016; Blosnich, Bossarte, and Silenzio 2012; Cochran et al. 2007; Graaf, Sandfort, and Have 2006; John Blosnich PhD and PhD 2012; Russell and Joyner 2001; Silenzio et al. 2007; Wichstrøm and Hegna 2003). The research of Plöderl et al. (2013) similarly found a relationship between sexual minority status and suicidal behavior. The Substance Abuse and Mental Health Services Administration as well as the World Health Organization recognize the LGBTQ community as an at-risk population for suicide, due to discrimination and sense of isolation (Lynsen 2014; WHO | Suicide). 
LGBTQ youth are especially at risk for suicidal behavior. Lesbian and gay youth are three times more likely than heterosexual youth to report feeling suicidal, and bisexual youth are five times more likely (Marshal et al. 2011). Nearly half (45\% of 55 participants) of all young transgender individuals (10-24 years) seriously contemplated suicide, and a quarter have attempted (Grossman and D'Augelli 2007). Young LGBTQ individuals who are highly rejected (no positive reactions) by their families are more than eight times as likely than those who experience low rejection to attempt suicide (Ryan 2009). Transgender individuals experience a rate of 57\% family rejection (Grant, Mottet, and Tanis 2011).

For transgender individuals, a high prevalence of suicide attempts over the lifetime was found across all demographics in the National Transgender Discrimination Survey (NTDS) (Grant et al. 2011). A majority (41\%) of all transgender respondents reported attempting suicide, as opposed to only $1.6 \%$ of the general population. Most (46\%) female-to-male transgender men and $42 \%$ of male-to-female transgender women have attempted suicide. The self-reported suicide attempt rate is $45 \%$ among younger adults (18-24), 54\% for multiracial individuals, and 56\% for American Indian or Alaskan Natives (Haas, Rodgers, and Herman 2014). Suicide attempts are also higher for those with low levels of educational attainment and/or low household incomes. Factors that exacerbate the risk of suicide attempts also include family rejection, discrimination, victimization, homelessness, violence at school, work, or when accessing health care, and violence from law enforcement (Haas et al. 2014). 
The transgender community is arguably one of the most marginalized minority groups, given the lack of protective laws and rights available to them. For example, the NTDS found that $78 \%$ of transgender children in grades K-12 report experiencing harassment, and 35\% report being the victims of physical assault. This victimization has caused $15 \%$ of transgender youth in grades K-12 to leave school. Additionally, many transgender individuals actively attempt to conceal their transgender identities in the workplace to avoid mistreatment, as $90 \%$ of transgender adults have experienced harassment, mistreatment, or discrimination at work. Over one quarter of respondents (26\%) have lost a job due to their gender identity and proportionally, transgender individuals experience the highest rate of homelessness. In fact, $55 \%$ of suicide attempts were made by transgender people who lost their jobs due to bias, $51 \%$ by those unemployed, and $60 \%$ of those who work in the underground economy. Other factors that contribute to high rates of homelessness among transgender individuals specifically include being refused a home or apartment (19\%) and being evicted due to gender identity (11\%). For those who found themselves homeless, 55\% were harassed by shelter staff or residents and $29 \%$ were turned away from them altogether.

LGBTQ communities are highly stigmatized worldwide. According to international reports ${ }^{1}, 76$ countries have laws criminalizing or persecuting LGBTQ people, and eight countries have death penalties for homosexual conduct (United Nations 2015). Sanders (1996) states that discrimination against lesbian women and gay men is a

\footnotetext{
${ }^{1}$ United Nations' Human Rights Council's 2015 Annual Report of the United Nations High Commissioner for Human Rights; Reports of the Office of the High Commissioner and the Secretary-General.
} 
more widely accepted form of discrimination when compared to racism and sexism around the world.

Even in the United States, LGBTQ individuals have less protective rights that vary heavily with state legislation. Same-sex marriage was only legalized nationwide in June 2015 in the Obergefell v. Hodges Supreme Court case (2015). Yet, this ruling still leaves LGBTQ Americans lacking in rights that affect their quality of life and safety in most states. These rights includes the possibility of being evicted from their homes, fired from their jobs, refused service in businesses, banned from fostering children, denied health insurance, and being victims of various hate crimes; all on account of their sexual or gender identity. According to the Movement Advance Project, only 20 states and Washington D.C. have passed laws outlawing employment and housing discrimination against individuals on the basis of both sexual orientation and gender (Movement Advancement Project | Equality Maps, Anon n.d.). Despite these steps, 28 states currently have no nondiscrimination laws protecting the LGBTQ community. Three states (Arkansas, Tennessee and North Carolina) even have laws that explicitly prevent the passage or enforcement of local nondiscrimination laws. Many states have nondiscrimination laws that protect sexual orientation minorities but exclude queer/gender non-conforming individuals, leaving this community far less protected and vulnerable.

As many discrimination codes do not protect gender identity, transgender and other gender non-conforming individuals have their own set of issues. For example, North Carolina's HB2 Bathroom Bill was passed on March 23, 2016, requiring 
transgender individuals to use the bathroom of their birth sex, and set ablaze an uproar of controversy across the nation. Former President Barack Obama’s administration publicized guidance on the issue, stating that under federal law, Title IX protects transgender children in schools and allows them to use the bathroom or locker room that they identify with. This controversial stance was revoked by the current President Donald Trump on February 23, 2017, however the HB2 Bill has since been repealed.

The sociopolitical climate continues to shape the health and wellness of LGBTQ individuals across the country, especially in regards to mental health and suicide. For example, the election of President Donald Trump and Vice President Mike Pence has elicited major concerns for this population, as they espouse conservative, anti-LGBTQ ideologies. This drastic political shift has resulted in a new landscape for LGBTQ mental health and wellbeing after Obama's progressive run. According to news outlets such as CNN, multiple crisis hotlines saw a dramatic surge of calls and texts after the election results were announced in November 2016 (Ravitz 2016). According to Ravitz's news story, The Trevor Project (a national LGBTQ youth suicide prevention service with call, text, and online chat options) received double the normal call volume. In addition, the Trans Lifeline, which normally receives 50 to 60 calls a day, was receiving 500 calls per day post-election.

LGBTQ individuals must navigate potential discrimination and victimization on institutional as well as personal levels. While LGBTQ individuals experience discrimination in the housing market, workplace, and legal system, they also experience marginalization on an interpersonal level. Due to the conservative and religious values 
tied to the concepts of marriage, sex, and gender roles, many individuals risk being ostracized by their social groups and disowned by family when they "come out," or reveal their LGBTQ identity.

Religious objections to homosexuality are often used to justify discrimination against sexual minorities (Sanders 1996). These values are sometimes so deeply rooted that many members of the LGBTQ community are at risk for being kicked out of their homes, abused, or forced to enroll in reparative (conversion) therapy. Families put their children through conversion therapy in hopes that it will 'fix' their child's sexual orientation or gender identity. However, conversion therapy is found to be harmful, and leaves detrimental psychological effects on patients. There is no empirical evidence of sexual orientation being successfully altered through these methods. Conversion therapy is rejected by almost every major medical, educational, mental health, counseling, and pediatric organization, and is even condemned by governmental divisions like the Substance Abuse and Mental Health Services Administration according to the Human Rights Campaign (HRC) website. Despite evidence of its harmfulness, only five states have laws banning conversion therapy for minors (Movement Advancement Project | Equality Maps).

According to the 2012 Homeless Youth Provider Survey, 40\% of all homeless youth identify as LGBTQ, and $43 \%$ of those youth became homeless due to being forced out by parents due to their LGBTQ identity. Many others experience physical, emotional, or sexual abuse at home, which is another contributing factor to LGBTQ youth homelessness (Durso and Gates 2012). Many individuals determine it is not safe to come 
out due to reasons already listed, and instead hide their identities from their families in order to avoid these circumstances. Feeling safe and able to express one's sexual identity and receive support from an accepting community is imperative to the development of mental well-being, and the cultivation of factors such as self-esteem, life satisfaction and inhibiting depression (Friedman \& Morgan 2009; Katz-Wise \& Hyde 2012; Mohr \& Fassinger 2003; Weston 1991).

The accumulation of negative experiences facing this population increases feelings of emotional distress, depression, self-harm and suicide ideation (Almeida, Johnson, Corliss, Molnar, \& Azrael, 2009). Researchers explain the increased prevalence of mental disorders within this group through the minority stress theory (Brooks 1981; Meyer 1995). This theory posits that stigma, prejudice, and discrimination create a stressful social environment that can lead to negative mental health outcomes (Friedman 1999). Coupled with a lack of coping skills and few support resources, the negative mental health outcomes for LGBTQ youth can lead to suicidal ideations and attempts.

The lack of social support for LGBTQ individuals due to stigma (and the resulting levels of high risk of suicide) can be explained by Durkheim's $(1897,1951)$ theory of suicide, which is based on his concepts of social integration, or the level in which a person feels accepted or connected to a group/society. He found that low levels of social integration result in higher rates of suicide, a pattern which is apparent in the LGBT population. Sexual minorities are not considered the norm in many societies, and are thus stigmatized. This stigma leads to LGBTQ communities being excluded and discriminated against, resulting in low levels of social integration. This stigma results in a lack of 
easily-accessible support resources (such as family or mental health services), and has pushed these socially isolated individuals to find indirect means of support (Cummings, Sproull, and Kiesler 2002; Williams et al. 2016).

Self-stigmatized fear of rejection of their identity is also linked with indirect support seeking (Williams et al. 2016). One indirect means of eliciting support comes from online resources. The use of online communication platforms brings together similar individuals to easily find social support from. These communities offer a social space for marginalized individuals to seek solutions, make friends, and also freely and openly express their identities.

\section{SOCIAL SUPPORT ONLINE}

Social support research continues as new types of social support groups emerge, specifically online. The internet is brimming with opportunity for communicating with like-minded people from all over the world, which creates a wealth of open-access data that can be analyzed for many different topics in various fields of research. The study of social support in online spaces is therefore diverse with a variety of populations and factors to examine.

In social support research, the elderly are commonly studied, as they make up a large portion of support communities online. Pfeil et al. (2011), for example, examined the social roles of older people in a support community online where support, information and gaining a sense of belonging become collective goods which drove the formation of these communities. Other researchers study social support groups for cancer, eating 
disorders, or mental illness (Finn and Steele 2010; Funch and Marshall 1983; Hull et al. 2016; Tong et al. 2013).

Commonly, especially among social scientists, these online communities are examined using social network analysis and theory, which focuses more on the flow of communication rather than message content. Eastin and LaRose (2005) used Albert Bandura's (1986) social cognitive theory to examine social cognitive factors such as selfefficacy to predict support activity, support reliance online, and network size and found these support systems to be complex and self-regulating.

Bambina (2007) addressed the theoretical paradox of online support groups. A number of theorists posit that computer-mediated communication (CMC) is too informal, distant, and comprised of weak-tied strangers to have the necessary characteristics of traditional social support groups. These necessary characteristics include a small size, a closed membership, immediacy of direct and recurrent contact, and the necessity of expressing feelings of emotional support and genuine companionship. However, there is a high prevalence of social support occurring online.

In her study of an online support group for cancer, Bambina found that emotional support and expressions of companionship occurred more than informational support, but that one had to be a regular and recognized member to receive equal support. This finding suggests that online support groups are indeed communities. In the case of social support for marginalized populations, weak ties, like those found in online support groups of strangers, allow people to safely disclose personal information online due to the diversity 
and social distance involved with interacting with others in these spaces (Walther and Boyd 2002).

The more stigma an individual experiences, the more likely they are to have negative psychological outcomes, like those of the LGBTQ community discussed in the previous section. These outcomes inevitably lead to the prevalence of stigmatized, and especially isolated, individuals to feel suicidal and actively share those ideations online. Many studies of social support online examining suicidal individuals have utilized either quantitative surveys, or quantitative content analysis of conversations between trained or professional counselors on professional websites to evaluate their effectiveness as a service for suicide prevention and offering support (Barak 2007; Fukkink 2011; Gilat and Shahar 2009).

\section{SOCIAL MEDIA}

Technology and social media have revolutionized social life. Much of the sociological literature examining the internet focuses on the negative effects that social media has produced, such as bullying, harassment, stalking, and even the suggestions that victims commit suicide (Westerlund, Hadlaczky, \& Wasserman, 2015). Although cyberbullying is an issue for LGBTQ individuals, social media is also used for creating community connections and safe spaces for expression. For example, a survey study of lesbian, gay, and bisexual internet-using help-seekers in Hong Kong used theories of social identity and minority stress to evaluate the significance of group membership for this community. The study found social media to be an important source of social capital for these individuals, and an alternate means of meeting various social and affective 
needs (Chong et al. 2015). This social capital takes the form of a sense of belonging, acceptance, and community, and is vital because the communities are built and structured by the community members themselves (Falk and Kilpatrick 2000). This sense of belonging helps alleviate negative effects, like suicidal ideation, caused by the lack of support through social integration by creating a community to socialize and identify with. The community serves as an outlet for emotional expression, stigma management, and means of informational and therapeutic help-seeking through peer-to-peer support (Pfeil et al. 2011; Walther and Boyd 2002). Community building, like that found online, has been found to be an important adaptive way of combatting this stigma (Frost and Meyer 2012).

In addition to seeking a community, there are multiple facets of socializing online that appeal to marginalized and invisible populations, including accessibility, anonymity, low cost, and the irrelevancy of social proximity, geographical distance, time, physical appearance, or visual cues (Barak 2007; McKenna and Bargh 2000a; Miller and Gergen 1998). Anonymity is the most important factor to these communities because it gives a stigmatized population the ability to hide their identity if they so choose. Anonymity facilitates a safe environment by erasing social markers which could normally stimulate prejudice. For the LGBTQ community, anonymity allows the ability to feel safe in expressing their identities and reaching out for emotional and motivational support (Hillier and Harrison 2007; McKenna and Bargh 2000a; Miller and Gergen 1998). Anonymity diminishes feelings of shame or self-consciousness that are associated with help-seeking offline for sensitive issues which makes it easier to share them than with 
offline peers. Online forums provide opportunity to express problems, engage with peers, read relevant stories, and receive advice at anytime and anywhere (Weinstein et al. 2016).

Accessibility is another key aspect of many social media groups that attracts

individuals who lack access to other means of support. Lack of access to social support in their physical reality pushes LGBTQ individuals to look for indirect means of obtaining social support. Nowadays, it is common to have access to the internet via personal computers, smartphones and tablet devices. This easy accessibility gives marginalized communities the ability to find immediate social support for no extra cost, beyond cellular or internet services.

\section{THE STUDY OF SUICIDE WITHIN SOCIOLOGY}

The study of suicide has been examined across multiple disciplines, especially within the social sciences, including sociology, anthropology, and social psychology. This interdisciplinary attention is due to the complex convergence of biological, psychological, sociological, and cultural elements that influence suicidal behaviors (Leenars 2002). The study of suicide was originally based on philosophy, and was not analyzed empirically until sociologist Emile Durkheim's Suicide (1897, 1951), which revolutionized the study of suicide (Fitzpatrick, Hooker, and Kerridge 2014). His research changed the way suicide was viewed and studied, as it was previously considered a primarily individual, psychological act, but is now understood as a collective, social phenomena. Durkheim discovered that suicide is related to social integration. Too much or too little integration can both result in suicide, albeit different 
types: low integration leads to egoistic suicide, while high integration leads to altruistic suicide.

Similar to Durkheim's theory of suicide, Thomas and Znaniecki (1920) found increased social disorganization and behavioral problems in displaced populations, such as immigrants, and Park and Burgess (1926) found the same in those forced to leave their home communities to find work. Others establish that the breakdown of social ties reduce social constraints and social resources based on social roles and norms (Brownell and Shumaker 1984; Heller 1979). This theoretical progress helps in understanding the high rates of suicide in stigmatized and marginalized minority communities, like that of the LGBTQ community. Durkheim's impactful analysis is still relevant to modern sociology, as contemporary researchers continue to rely on his theory of suicide for analyzing other suicidal phenomena, such as suicide within family units or suicide related to unemployment or divorce (Breault 1986; Danigelis and Pope 1979; Kposowa 2000; Maimon and Kuhl 2008; Maris 1981; Wasserman 1984).

Differentially, Scandinavian suicidologists Knizek \& Hjelmeland (2007) conceptualize suicidal behaviors as deliberate acts of communication, not simply selfdestruction. Owen et al. (2012) states that the responses to suicidal communications from those not in contact with mental health services need to be researched further. Naslund et al. (2016) also describes the necessity of research focusing on online peer-to-peer support as it may be the only way to reach such a socially isolated, at-risk population like suicidal LGBTQ individuals. Following these calls to action, the present study examines suicidal 
individuals who are actively reaching out for help with their suicidal ideations in an online community. 


\section{Chapter 3. Theoretical Framework}

This chapter discusses the history of social support theory and how it is being studied today by various disciplines. It then outlines the two models of the social support theory reviewed by Cohen and Wills (1985) and Cohen and McKay (1984): the main, or direct, effect model, and the stress-buffering model. An in-depth explanation of the stress-buffering model is provided in order to allow understanding of its applicability in this study. Lastly, an overview of functioning buffer mechanism, their definitions, and categorizations are provided.

\section{THE HISTORY OF SOCIAL SUPPORT THEORY}

Social support, defined broadly, refers to any processes in which the promotion of health and wellbeing is stimulated by social relationships (Gottlieb et al. 2000). The social support theory began with John Cassel (1976) and Sidney Cobb's (1976) notions that strong social ties, which stimulate feelings of belonging, esteem, and love protect individuals from pathogenic effects resulting from stressful experiences. The theory's main hypothesis, the buffering hypothesis, asserts that persons with high stress and low support will show disproportionately elevated symptomatology (Cohen and Wills 1985). Though the study of social support is common in the fields of psychology and social psychology, it has roots in the sociological tradition (Gottlieb et al. 2000). Classical sociologists Emile Durkheim (1897, 1951), George Herbert Mead (1935), and Charles Horton Cooley (1902), for example, viewed individual phenomena as part of a larger collective human experience. Durkheim in particular found that suicide was a 
consequence of too little or too much social integration, or social network participation, in society.

The formation and function of social groups is also influenced by symbolic interactionist theories. For example, Mead's (1935) analysis of symbolic interactionism suggests that the creation of the human mind and self is a reflection of individuals' interactions with others. Cooley (1902) introduced the concept of the "looking-glass self" which holds that the development of the "self" and identity is shaped by the social interactions with others and is crucial to one's development and wellbeing. Health and wellbeing are heavily influenced by how humans fit into social groups and the interactions had among them.

In addition to symbolic interactionism, researchers of the cognitive tradition examined the effects of stressful life events in relation to social integration, network ties, and available social support. There was a surge of interest in the study of social support among social psychologists and epidemiologists in the 1970's and 80's. Several studies found that those who participate in society more have better mental health than those who are more isolated (Bell, Leroy, and Stephenson 1982; Cohen and Wills 1985a; Miller and Ingham 1979). One's social integration was measured on the basis of diversity of ones' relationships (such as a spouse, family, friends, and social group members, like religious groups). Cassel (1976) suggested that the impact of stress was mitigated by having consistent communication of support, assistance, rewards, and evaluations of their performance. Cobb (1976) likewise argued that those who perceived communication from others as loving, caring, and showing that they were valued and belonged were 
more protected from the risks from stressful life events because these perceptions facilitate coping and adaptation skills.

Since Cassel and Cobb's assertions, two camps of hypothesis testing for the social support theory's buffering hypothesis were created: proponents of the main, or direct, effect of social support on wellbeing (Berkman, Breslow, and Wingard 1983; Cohen, Teresi, and Holmes 1987; White and Cant 2003), and those of the stress-buffering effect of social support (Landman-Peeters et al. 2005; Lin et al. 1979; Orth-Gomér 1994; Wallace 2005). Cohen and Wills' (1985) review of over 40 studies testing these effects found that both are viable models and means for social support to intervene in the pathway from stress to pathological outcomes, but have different levels of effectiveness depending on context. The stress-buffering model is used as the main theoretical framework in this study.

Contemporary sociologist Horwitz (1984) created a general theory of therapy and social solidarity based on Black's general theory of social control, which views social support as a form of social control. Other sociologists have continued to add to the general literature of social support mainly through the study of social network analyses, specifically how network characteristics affect access to social support (Granovetter 1973; Wellman and Gulia 1999). This line of research led to the investigation of social support in online networks.

\section{SOCIAL SUPPORT THEORY}

Cohen and Wills (1985) reviewed social support studies according to whether the measures used assessed support structure, or the existence of relationships, function, the 
extent to which relationships provide resources, and globality of the scales, or the degree of specificity ${ }^{1}$. They concluded that there is sufficient evidence for both models, but the models represent different processes through which social support affects wellbeing. The main-effect model works by assessing the degree in which a person is integrated in their network, while the buffering model works by assessing one's perception that they have available resources that are responsive to their needs after a stressful event or in the anticipation of a stressful event.

The main-effect model, similar to Durkheim's focus, conceptualized social support as a regularized social interaction related to overall embeddedness within society. It posits that social support creates a generalized beneficial effect due to regular positive experiences and a stable set of connections, interactions and roles within a community. This presumed avoidance of negative experiences in turn creates predictability and stability in one's life leading to a greater sense of self-worth through role fulfillment. This model is best used when showing purely structural measures related to the existence and number of network connections, though it does not provide any other sensitive measures of the functions and quality of the community ties.

The stress buffering model, however, states that support mediates a stressful event, or the perceived anticipation of one, by preventing and attenuating a response. This can occur in number of ways, including altering appraisal of stressors, changing coping patterns, or affecting self-perceptions. Cohen and Wills' definition of stress includes,

\footnotetext{
${ }^{1}$ Specificity indicates if a measure assesses a specific function or structure, or if it combines multiple measures into an undifferentiated global index.
} 
"link(ing) appraised stress with feelings of helplessness and the possible loss of selfesteem (1985:312)," due to a perceived inability to cope with the stressful event. By receiving appropriate forms of social support, negative effects of stress can be alleviated through functioning buffer mechanisms that match the needs of the stressed individual by providing solutions to the problem, changing their perception of the situation by trying to focus their attention on more positive aspects of their troubling situation (Pearlin and Schooler 1978), or distracting them from the issue (Gottlieb et al. 2000). Support can also be provided by convincing individuals that they do indeed have the appropriate coping skills to respond to the stressful situation, or that a failure to respond is not that important (Sells 1970).

Consistent evidence for the stress-buffering effect was found in studies that measure the perceived availability of support that matched one's needs. The evidence suggests that whether one actually receives the proper support is less important than the perception that they have support if they need it. Most of the studies reviewed using the buffering hypothesis did not measure discrete events, but rather cumulative measures from life events scales and checklists, under the assumption that illness is related to cumulative stressful experiences. Cohen and Wills conclude that buffering effects can only be observed when there is a reliable index of broadly useful esteem or informational support functions, or buffer mechanisms. 


\section{THE STRESS-BUFFERING MODEL}

Stress Appraisal Process

Cohen and McKay (1984) offer a theoretical analysis of the mechanisms that protect individuals from stress-induced pathology through interpersonal relationships. They provide a multidimensional view and focus on the functional relationships between the coping needed from a stressful event and the support provided by one's network. They agree with Lazarus (1966) in that stress occurs as a result of appraising a situation as threatening and not having the proper coping response, as well as Sells' (1970) assumption that the consequences of failing to respond appropriately are very important.

Distinctions are made between a stressful event, the experience of stress due to the event or the anticipation of it, and the onset of pathological. For LGBTQ individuals, an example of a stressful event could be an individual coming out to their family as LGBTQ. The experience of stress as a result of not having the proper coping response to the stressor includes outcomes like physiological elevation and behavioral adaptations. This conceptualization also addresses the anticipation of a stressful event, as it can still cause stress responses. The anticipation of coming out to someone and the inner turmoil many LGBTQ individuals experience may be enough to cause suicidal ideations, especially if they know that the risk for rejection is high.

In the stress-buffering model, there are two points in the causal chain of stress where support intervenes (Cohen and McKay 1984). Intervention may occur either between a stressful event (or the expectation of it) and the person's reaction to it, or between the experience of the stress from the event and the onset of a pathological 
outcome. Figure 1. provides an illustration of these intervention pathways and how it relates to the phenomena investigated in the present study. The interferences work through buffer mechanisms. In this study, the pathological outcomes for LGBTQ individuals include depression and other mental illnesses that contribute to suicidal ideations, as well as the ideations themselves. Cohen and McKay conceptualize the pathological effects generally, and the buffering hypothesis is not related to any specific psychological disorder. This conceptualization allows focus to stay on stressors and interpersonal relationships, and also allows for applicability to other outcomes like suicidal ideations.

Figure 1. Stress-Buffering Model: How Social Support Intervenes in the Causal Link between (LGBTQ) Stressful Events and Pathological Outcomes (Suicide Attempts)

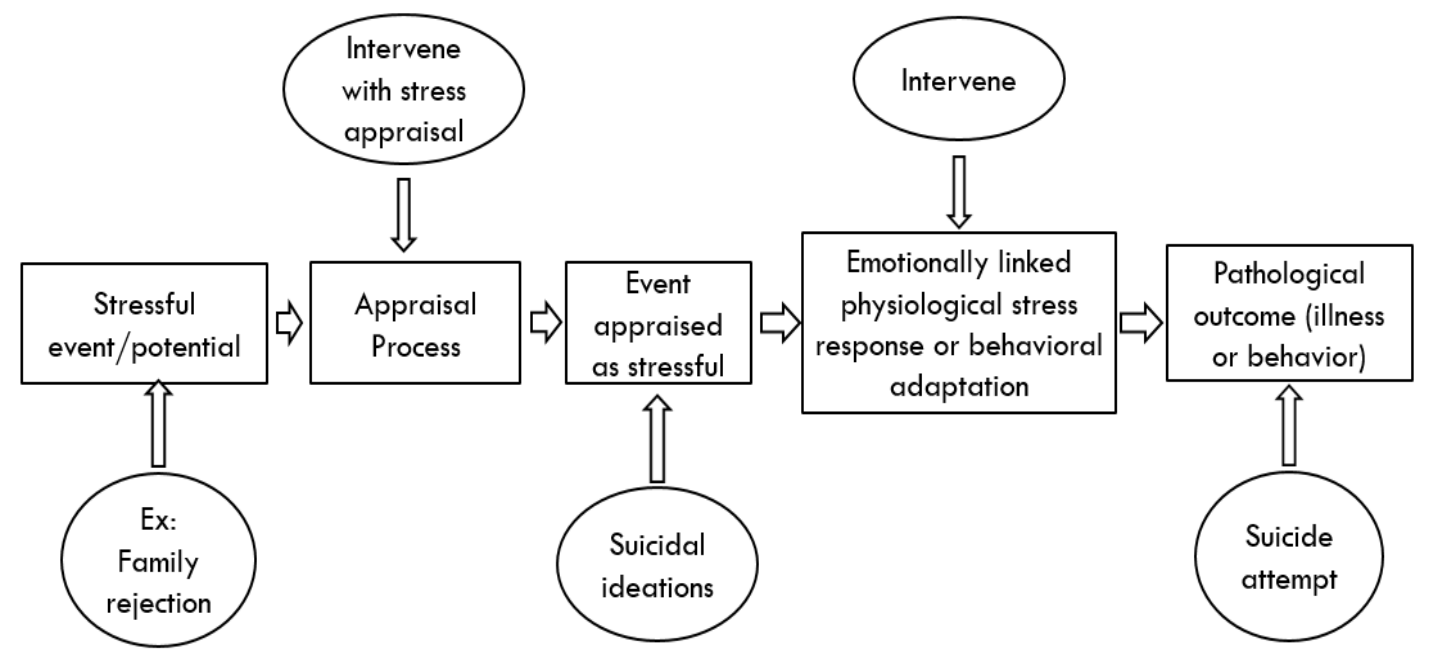

\section{Matching Support to Needs}

The key to the buffering model is that "there must be a reasonable match between the coping requirements and the available support in order for buffering to occur" (Cohen \& Wills 1985:314). Evidence of an effective stress-buffering effect is observed when 
buffer mechanisms are most relevant for the particular stressful event an individual is facing. It is important to note that these support functions do not always occur independently of one another, but may work together to answer multiple needs.

There are many different buffer mechanisms categorized by researchers, but they all contain similar comprehensive themes. Various theme categories include emotional, informational, companionship, esteem support, and tangible support, and more (Braithwaite, Waldron, and Finn 1999; Cobb 1976; Cohen and Wills 1985b; Cutrona and Russell 1990; Cutrona and Suhr 1992; House and 1944- 1981; Reber 1995). Cutrona and Suhr (1994) and Lazarus and Folkman (1984) reduce these categories to a simplified binary structure of problem-focused and emotion-focused coping, and action-facilitating and nurturant support.

Caplan (1979) and Cobb (1976) distinguish between psychological support, referring to the provision of information, and non-psychological forms of support, referring to tangible or material aid. They discuss tangible aid as most effective when material aid is considered appropriate by the recipient. In contrast, Cohen and McKay view the psychological perspective not as providing new coping strategies immediately, but attempts to change one's perception of the situation and ability to cope, as well as assures the individual that support is available. The psychological forms are divided further into appraisal and emotional support. Appraisal support contributes to one's body of knowledge, while emotional support works to meet one's basic socio-emotional needs.

The work of Cohen and McKay focus on these similar categories in their theoretical analysis of the buffering hypothesis. Appraisal support interferes with stress 
and its effects by reappraising the stressful situation as benign. This support category is influenced by Lazarus' (1966) cognitive model of stressor appraisal, which states that the experience of psychological stress depends on how potentially threatening a situation is evaluated. Since the experience of stress hinges both the assessment and coping abilities, social support interferes by altering one or both of these. A potential example of this could involve someone being afraid to come out to their family because of their family's anti-LGBTQ beliefs. Appraisal support could intervene by either changing their assumptions that their family will not accept them, or by giving advice on how to approach their family.

Cobb's (1979) definition of support exemplifies the category of emotional support. He defines support as information that encourages one to feel or believe that they are cared for, loved, valued, esteemed, and that they belong (to a group). This definition is different than appraisal support because it emphasizes one's evaluation and feelings, rather than the situation. Within this frame, social support protects or helps one recover from "emotional losses" that occur as a result of a stressful event. Emotional loss has been studied in the terms of its effects on overall well-being, which shows the important role of feelings of control and self-esteem in resistance and recovery from illness.

The concept of emotional loss is also related to self-esteem. A method of social support that is related to self-esteem is raising an individual's awareness of their selfefficacy. Cohen and McKay emphasize the importance of identifying stressful conditions that result in negative feelings about one's self. Abramson, Seligman, and Teasdale 
(1978) suggest that those who attribute their inability to cope or control a situation internally results in low levels of self-esteem. The negative societal attitudes that affect the LGBTQ population, however, adds a different twist on this concept of self-esteem. This is largely because LGBTQ individuals may feel powerless in shaping the perceptions of others when it comes to their identities. Suicidal ideations are often caused by feelings of helplessness in a situation, or by low levels of self-esteem, both of which affect individuals within this study.

Cohen and Wills (1985) use the categories of esteem support, informational support, social companionship and instrumental aid in their work, but explain that esteem support and informational support are applicable to a wider range of stress-inducing events. Esteem support (also referred to as emotional, expressive, self-esteem, ventilation or close support) works to counterbalance threats to self-esteem that result from either the anticipation of a stressful event, or the stressful event itself. In the online social support literature, esteem support is often subsumed under emotional support (Bambina 2007). Informational support (also called advice, appraisal support, or cognitive guidance) works to counter an individual's perceived lack of control in a situation by redefining the stressful situation as nonthreatening, or by making suggestions for more appropriate coping responses.

Cohen and McKay also discuss a situation in which methods of social comparison can act as a buffer mechanism. The use of social comparison as a buffer mechanism is only applicable when an individual turns to others who have experienced something similar. There is, however, debate among social support researchers as to whether upward 
comparisons are helpful. Wills (1981) suggests that downward comparisons may enhance one's own subjective well-being, while Cohen and McKay agree that upward comparison may be more harmful than helpful if one does not "measure up" to another's progress or coping abilities.

Social companionship (diffuse support or belongingness) takes the form of spending time with others. This reduces stress by filling a person's need for belonging, distracting them from their stressors, or facilitating a positive mood. Cohen and McKay suggest that feelings of belonging and solidarity have general positive effects on mood, and therefore can help maintain a minimum level of wellbeing and guard against stressinduced psychological disorders like depression. If the stressor deprives an individual of a sense of community, companionship can provide the sense of solidarity that is essential to an individual's well-being.

Lastly, instrumental aid (material support or tangible support) is financial or material support and can be a direct resolution to a problem if the stressors are caused solely by financial or material deprivation. In literature of social support in online spaces, however, tangible support is less common due to the interactions not taking place in the physical world (Bambina 2007).

The buffer mechanism categories utilized in this study are explained in the next chapter and are listed in Table 1 . on page 40. 


\section{Chapter 4. Methodology}

This chapter begins by outlining the objectives of this study and defines the method of qualitative content analysis. It then describes the data source, LGBTchat.net, and explains the data collection and sampling methods, as well as the procedures for coding and analyzing the online communication threads under the stress-buffering theoretical framework. Lastly, ethical considerations and limitations of the study are put forth.

\section{RESEARCH OBJECTIVES}

The main objective of this research is to evaluate the helpfulness of social support responses provided to suicidal LGBTQ help-seekers in an online forum based on the stress buffering model of the social support theory. In their suggestions for future research, Cohen and Wills state that they wished to know how and where social support transactions occur, and also suggest that both qualitative and quantitative approaches to research on social networks would provide valuable perspectives. Therefore, this research tests the stress-buffering framework qualitatively by measuring social support in a virtual setting, where direct observation of written interactions are possible. At the time of their research, such direct evidence was difficult to acquire, but public internet forums now provide appropriate mediums for studying social support phenomena.

\section{QUALITATIVE CONTENT ANALYSIS}

This study utilizes qualitative content analysis of LGBTchat.net in order to find evidence of a buffering effect on stress in suicidal LGBTQ individuals online. Content analysis is a systematic method of analyzing verbal, visual, or written communication 
interactions, and can be used to identify and describe patterns in data as well as make inferences about meaning, intentions, consequences, context, and effects (Elo S and Kyngäs H 2008; Herring 2009). Qualitative content analysis, as opposed to quantitative, concentrates on themes, topics, categories and distribution found within data, as well as the meanings and relations between them. This form complements and supports quantitative research because quantitative methods do not account for meaning in data and provide overall pictures of data (Pfeil and Zaphiris 2009).

The internet now provides another medium for using content analysis to analyze readily available data. In this method, a sample is selected, coding categories are defined for words or phrases that share a similar meaning of interest, and then the collected data is coded, analyzed, and interpreted. Content analysis allows theoretical testing in order to enhance understanding of data. This study uses a directed, or deductive approach, meaning the coding categories are theoretically pre-focused based on the literature of the stress-buffering model and move from general to specific (Elo S and Kyngäs H 2008; Hsieh and Shannon 2005). The unit of analysis for this study are the messages within the thread postings by suicidal LGBTQ individuals in the forum of LGBTchat.net. This includes the original posts, as well as the subsequent responses to them.

\section{DATA SOURCE: LGBTCHAT.NET}

The website chosen for analyzing support responses to suicidal LGBTQ individuals online is LBGTchat.net, an open chat and forum website specifically created for those with an LGBTQ identity to network and discuss a variety of topics. This site was chosen for multiple reasons, including its popularity, easy public access, user 
anonymity options, target specificity, and ease of navigation. Based on Weare and Lin's (2000) recommendation to focus on the most popularly used sites on the web that have available access, this site was chosen after an internet search of the keywords "LGBT support group online." LGBTchat.net was the first unsponsored option. This search result implies that it is both the most relevant site to the search terms, as well as the most popular and visited site for this search.

Additionally, at the bottom of the website, there is a box titled "Users found this site by searching for:" with a long list of key phrases of a similar variation, including "lgbt support chat", "lgbt support forum", "lgbt support groups online”, and "gay community online". This information demonstrates that this site contains users looking for an online LGBTQ-specific community for the purposes of discussion and finding support from a community that shares their identity. The threads on this website do not require a visitor to have an account in order to view them, making it simple to find threads of interest. It also mitigates any observer effects, as it is not necessary to interact with other users. The structure of the website was also helpful in that it provides users the ability to search for topics and keywords within forum threads.

The forum discussion threads are categorized under three main headings: “General," "The Community," and "Groups." "General” includes general discussions with sub categories including General (Off-Topic Lounge), Introduce Yourself, News \& Politics, Funny, Gaymers, and TV \& Music. "The Community" includes the categories Questioning and General LGBT, Lesbian, Gay, Bisexual, Transgender, Pansexual, and Heterosexual. "Groups" include more private discussions and has only one subcategory, 
Group Discussions. From the group's home page, it is possible to see how many discussions and messages are in each category to date in the left column, and the title of the latest thread post, the username of the poster, and the time stamp on the right column. Introduce Yourself and General (Off-Topic Lounge) are the most active forums, and the threads of interest to this study were mostly found in the latter.

\section{Common Issues}

The original posters within the sample threads faced a series of common issues due to their LGBTQ status. Many of the issues reflect those discussed in the literature review. The most common issues were those of family rejection (or the anticipation of it), depression, and identity concealment, which reflect the literature of factors that may lead to suicidal ideations. The finding of frequent family rejection among these suicidal individuals correlates with the statistic that LGBTQ individuals are eight times as likely to attempt suicide if they are rejected by their family for their identity (Ryan 2009). High amounts of depression in this sample reflects the negative effects of all these common issues on LGBTQ mental health and wellbeing, as well as its connection to suicidal ideations.

The most common issue in posts expressing emotional support needs was loneliness. This pattern demonstrates how isolated these individuals are and why they may be turning to an online community for support. The most common issue for informational needs was family rejection. Identity concealment was the most common for threads indicating both emotional and informational support needs, which exemplifies how difficult it is for these individuals to openly live their lives as who they are, many of 
them doing so for their safety. Other issues presented in this data included bullying/harassment, low self-esteem, internalized homophobia, dysphoria, relationship problems, coming out, homelessness, self-harm, problems with transitioning for transgender individuals, abuse, and fear. Many of the issues were transgender-specific as many of participants were transgender. The large amount of posts written by transgender individuals also reflect the high statistics for transgender individuals feeling suicidal presented in the literature review.

\section{DATA COLLECTION}

The specific topic of interest for this study makes random sampling inappropriate. However, it is common for studies using content analysis of websites to not use random sampling (Herring 2009). Collection procedures were guided by the following protocol: a thread posted by a suicidal individual indicating that they were suicidal, directly or indirectly, followed by various responses of support by other users. In order to locate such precise threads, related keywords were typed into the search box provided by the website. The following relevant keywords (in order) were used: suicide, kill myself, suicidal, and hurt myself.

At the time of final collection, there were 14,616 users, 14,411 total discussions, and 107,830 messages sent. Searching the keyword suicide resulted in 180 hits, covering nine pages of results. The time stamps of the results spanned from July 26, 2013 to November 23, 2016. However, not all results found through these keywords are included in the sample. Each result was closely examined, and only posts where the original poster of the thread expressed suicidal ideations and receiving responses are included. 
Keywords were found either in the title of the thread or within the comments. Reading through each thread was necessary to determine if it fit within the collection protocol.

Additionally, search results were often repeated due to the similar subject matter and more than one of the keywords being used within the same thread. In this case, results were only included once in the first keyword group. Therefore, 27 out of 180 thread results for keyword suicide are included in the sample (posting dates spanned from August 27, 2014 to November 11, 2016). The keywords kill myself yielded 29 instances across two pages of results ranging from August 20, 2013 to November 10, 2016. Out of these results, only one thread was included, per the collection protocol, with a posting date of June 13, 2016. Keyword suicidal yielded 89 results across five pages from March 13, 2014 to November 17, 2016. Of these, 7 were used, ranging from September 11, 2015 to October 13, 2016. Lastly, keywords hurt myself produced 198 results across 10 pages, ranging from August 10, 2016 to November 26, 2016. There was only one thread collected from this with a posting date of October 4, 2016. This search resulted in a sample of 36 threads total.

\section{THE SAMPLE}

This study focuses on the thread content and responses to suicidal ideations rather than the participants themselves. The authors of the collected thread posts are referred to as the original posters (called OPs), and the individuals who comment on the posts are labeled responders. Demographic information about these individuals is not provided, because the demographic details are inconsistent due to users' choice of anonymity. In addition, the factor of arbitrary honesty about one's real identity online also affects the 
validity of self-representation. There is no way of affirming a participant's age, even if it is provided on one's profile. However, the website requires users of the site to be at least 13 years of age. Therefore, participants include adults and adolescents. It is also known that participants can be from any country, and there are some from countries outside of the United States, such as Russia. Despite these issues, appropriate user information will be presented when available and appropriate in the results. Fortunately, the only truly necessary demographic information is a sexual minority identity to assure that the target group has been obtained, and this is assumed through use of the LGBTQ specific forum.

\section{METHODS}

The buffering hypothesis posits that negative effects of stress can be alleviated through functioning buffer mechanisms that match the needs of the stressed individual. Stress buffering is contingent upon the presence of a match between the form of support offered and the need of the individual under stress. Therefore, there may only be evidence of a buffering effect when the buffer mechanism is relevant to the stressor. For example, an individual suffering with a loss of self-esteem due to bullying would most likely need emotional social support. If an individual needs advice on how to come out as gay to their parents, an informational support response would be the most appropriate. Therefore, responses will be evaluated as unmatched and unhelpful if there is no evidence of stressbuffering based on no match found between the OP's need and the responders' support provided. If there is evidence of stress-buffering occurring based on a match between support mechanisms, then those comments are evaluated as matched and helpful. 


\section{Coding}

The buffer mechanisms employed in social support interactions provide a range of opportunities to lend someone support and decrease their levels of stress. The prior chapter discussed the various ways different researchers have conceptualized and categorized buffer mechanisms. The present study reduces these overlapping categories into two broader categories of either emotional support, or informational support. This is due to Cohen and Will's assertion that esteem (emotional) and informational support are more responsive to a wide range of stressful situations This binary categorization is similar to Cutrona and Suhr's (1994) and Lazarus and Folkman's (1984) conceptualization of forms of support and coping. There are various ways in which each support category presents itself in the data, which are aligned with the mechanisms provided by Cohen and Wills and Cohen and MacKay, including esteem support, social companionship, social comparison, advice, and reappraisal.

Cohen and Wills also point out that the perception of support operates as a buffer, and may be more important than the actual support. Therefore, it is included in the coding scheme. Evidence of buffering through perceived support is signified through messages where the $\mathrm{OP}$ communicates that they perceive that support is available or that the support they received was helpful. An example of this type of validating response would be an individual replying, "Wow, it is great to know that I have people like you there for me next time I need you." However, because these messages are not always provided, analysis is still only contingent on the presence of matched support to needs. Table 1. 
provides the coding scheme based on the binary support categories, and the resulting subthemes found within each.

Table 1. Coding Scheme

\begin{tabular}{|c|c|c|}
\hline Codes & Definition & Examples \\
\hline \multicolumn{3}{|c|}{$\begin{array}{l}\text { Emotional Support: Information that encourages one to feel or believe that they are cared for, } \\
\text { loved, valued, and that they belong. It emphasizes one's feelings and protects or helps one recover } \\
\text { from "emotional losses" that occur as a result of a stressful event. }\end{array}$} \\
\hline Esteem Support & $\begin{array}{l}\text { Counterbalances threats to self- } \\
\text { esteem by emphasizes one's } \\
\text { evaluation and feelings about } \\
\text { themselves or raising one's } \\
\text { awareness of their self-efficacy to } \\
\text { conquer their problem. }\end{array}$ & $\begin{array}{l}\text { "You are amazing and unique. } \\
\text { Don't let anyone tell you } \\
\text { differently" }\end{array}$ \\
\hline Social Companionship & $\begin{array}{l}\text { Facilitating feelings of belonging } \\
\text { and solidarity; offering friendship or } \\
\text { future support }\end{array}$ & $\begin{array}{l}\text { "I'm always here if you ever } \\
\text { need someone to talk to.. Feel } \\
\text { free to message me anytime." }\end{array}$ \\
\hline Reappraisal & $\begin{array}{l}\text { Attempting to change OP's } \\
\text { perception of situation or lack of } \\
\text { control in a situations }\end{array}$ & $\begin{array}{l}\text { "If they stop being friends } \\
\text { with you because you're gay, } \\
\text { they weren't your true friends } \\
\text { and you don't need anyone } \\
\text { like that." }\end{array}$ \\
\hline -Condemning & $\begin{array}{l}\text { Communicating a disdain towards } \\
\text { an OP for feeling suicidal based on } \\
\text { own }\end{array}$ & $\begin{array}{l}\text { "Killing yourself is selfish } \\
\text { and only cowards do that." }\end{array}$ \\
\hline Social Comparison & $\begin{array}{l}\text { Communicating that one relates to } \\
\text { an OP's feelings or experiences } \\
\text { opinion }\end{array}$ & $\begin{array}{l}\text { "I've also had thoughts about } \\
\text { killing myself. I never thought } \\
\text { I could continue on, but I'm } \\
\text { still here" }\end{array}$ \\
\hline
\end{tabular}




\begin{tabular}{|l|l|l|}
\hline Advice & $\begin{array}{l}\text { Providing suggestions for better } \\
\text { coping responses or action that } \\
\text { could be taken to solve problems }\end{array}$ & $\begin{array}{l}\text { "Maybe googling a list of } \\
\text { coping skills would help, so } \\
\text { you have other things to fall } \\
\text { back on" }\end{array}$ \\
-Referral & $\begin{array}{l}\text { Recommendation to specific } \\
\text { resources outside of the forum } \\
\text { Perceived Support }\end{array}$ & $\begin{array}{l}\text { "Call the Trevor Project at 1- } \\
\text { 866-488-7386 or Suicide } \\
\text { Prevention Lifeline at 1-800- } \\
\text { 273-8255 they will help you" } \\
\text { that support was helpful }\end{array}$ \\
\hline
\end{tabular}

Analytic Procedure

The first step in the analytic process of this qualitative content analysis was the coding of the OP's need, provided by their thread posting, for either emotional or informational support. It is important to note that there were often thread postings conveying both needs. Thread postings coded for emotional support need strictly communicated emotional needs, such as feeling lonely or communicating feeling unloved or cared for. Strictly emotional threads do not include OPs asking for advice, or any other element that would add an informational factor to it. Thread postings coded as needing informational support strictly conveyed informational needs only such as asking for advice. Threads including indicators of both needs, for example, may have been communicated by OPs putting themselves down, which is an indicator for emotional support, and then asking for advice, which is an indicator of a need for informational 
support. Table 2. shows examples of thread posts exhibiting the need for each code category.

Table 2. Original Poster Need Codes

\begin{tabular}{|c|c|c|}
\hline Code & Example Thread & Indicators \\
\hline Emotional & $\begin{array}{l}\text { Please help me... I feel so useless. I don't think anyone } \\
\text { likes me anymore. I try to make friends but it never works. } \\
\text { I hate my voice, my body, everything about myself. I've } \\
\text { gotten to the point where I think about killing myself... I } \\
\text { really need someone }\end{array}$ & $\begin{array}{l}\text { - I feel so useless and I hate } \\
\text { my voice, my body, } \\
\text { everything about myself = } \\
\text { emotional need } \\
\text { - I try to make friends but it } \\
\text { never works and I really } \\
\text { need someone= emotional } \\
\text { need }\end{array}$ \\
\hline Informational & $\begin{array}{l}\text { For } 5 \text { months I've been in a very deep depression. I have } \\
\text { made plans to kill myself and today after I got home I } \\
\text { realized how close I actually was to doing it at school. I } \\
\text { planned to use a belt to hang myself. I still really want to } \\
\text { die. I was so close to doing it and the thought of hurting my } \\
\text { parents is the only thing that stopped me. Because of this I } \\
\text { know I have to get help. I want to tell my mother that I } \\
\text { should go to the hospital, but I can't stand that thought of } \\
\text { how much it would hurt her. Just the fact of my friends } \\
\text { going because of attempts and ideations upset her so much. } \\
\text { I can't stand thinking about how her possible reaction to it } \\
\text { being her own child. How should I ask her for help? }\end{array}$ & $\begin{array}{l}\text { How should I ask her for } \\
\text { help?= informational need }\end{array}$ \\
\hline Multiple Needs & $\begin{array}{l}\text { I think about killing myself sometimes. Is that bad? People } \\
\text { would probably forget about me eventually... god I'm so } \\
\text { depressed. My "friends" weren't helpful and my } \\
\text { psychologist blocked me that bitch. She was helping me } \\
\text { pro bono but I guess she was tired of not being paid. She } \\
\text { really disappointed me. My heart is broken by the girl that I } \\
\text { love, she's also ignoring me. I guess she didn't care for me } \\
\text { like I thought she did.. like I did for her. I just want her } \\
\text { back. What should I do? }\end{array}$ & $\begin{array}{l}\text { - People would probably } \\
\text { forget about me eventually= } \\
\text { emotional need } \\
\text { - My "friends" weren't helpful } \\
\text { and my psychologist blocked } \\
\text { me that bitch= emotional } \\
\text { - My heart is broken by the } \\
\text { girl that I love, she's also } \\
\text { ignoring me. I guess she } \\
\text { didn't care for me like I } \\
\text { thought she did.. like I did } \\
\text { for her = emotional need } \\
\text { - What should I do?= } \\
\text { informational need }\end{array}$ \\
\hline
\end{tabular}


The second step in this research study was to code the responses for the form of support they were providing (emotional or informational). The last step was to analyze the coded data for matches between the needs conveyed and the mechanisms provided to evaluate whether or not stress-buffering occurred.

\section{ETHICAL CONSIDERATIONS}

As stated in the data source section above, LGTQchat.net was chosen due to the open access aspect of the threads. Any internet user may use this site and view the forum discussions. Users of the site are aware of availability of information, and still choose to discuss and disclose sensitive topics. This public access makes it possible to collect data without interfering with participants in their natural setting. It also removes the need for IRB approval and informed consent from participants to use their discussions for content analysis research.

Participants of this stigmatized population may feel comfortable disclosing sensitive issues and details with strangers on this publically accessible site because of the anonymity feature option of their profile. Users can create and edit their profile to display themselves however they wish with a customizable username, profile picture, location, and biography. Users often do not use their real names or pictures of themselves in order to protect their identity. This anonymity encourages users to feel safer disclosing information about themselves, such as the suicidal feelings that this research focuses on. This behavior is consistent with findings that anonymity increases the degree of feeling safe to self-disclose (McKenna and Bargh 2000; Spears and Lea 1994). 
However, this also poses some potential privacy issues for the participants. The anonymity feature protects participants' real identities to some degree, but not everyone chooses to be completely anonymous. Therefore, per Pfeil and Zaphiris's (2009) example after a discussion of participant protection and ethics, the real usernames will not be used. Additionally, direct quotations may be modified, but not so drastically as to lose the meaning of them in context.

\section{LIMITATIONS}

The qualitative nature of this research and the sample size of 36 threads limits the generalizability of the findings to all social support interactions online. The lack of demographic information about the sample participants also inhibit the strength of the claims made for the sub-populations observed within the forum. In addition, the LGBTQspecific population makes the findings inapplicable to other populations due to the unique issues these individuals face.

Moreover, LGBTchat.net itself is not just an online support group, but an LGBTQ-specific chat website with a wide range of discussion topics. Thus, the support offered here cannot be applied to other support group specific sites. Reliability of this study is also hindered due to the fact that there is not consistent evidence of validated perceived support from OPs, but rather is contingent on the match between need and provided support. Furthermore, the nature of content analysis and the researcher being removed from the participants inhibits the gathering of any health data post-analysis that may relate to stress. 


\section{Chapter 5. Results}

This chapter provides the results found through applying the stress-buffering model qualitatively to investigate the helpfulness of social support responses to suicidal postings in LGBTchat.net. Every thread included in the sample was found to be matched between the OP's need(s) and the social support provided. Examples of matches for both emotional and informational needs are provided as well as descriptions of the variations found within each form of support with examples. Also provided are examples of comments indicating perceived support from OPs and examples of unmatched comments.

\section{MATCHED RESPONSES}

Threads disclosing suicidal ideations were first coded by the support need that the OPs conveyed as either emotional, informational, or both. There were 19 threads with purely emotional needs, nine threads with purely informational needs, and 12 threads including both needs. Matches between the coded need and the coded support buffer mechanisms used in each comment were analyzed in order to conclude whether the support responses these suicidal individuals are receiving are helpful or not in buffering stress, and ultimately avoiding a suicide attempt. The results of the provided support given to these individuals are overwhelmingly matched. Every thread (36) was matched with the form of support that was needed as conveyed by the OP, even threads eliciting both forms of support. This means that the comments under a thread posting as a whole provided the correct form of support to match the need by the end of the thread. 


\section{Emotional Support}

Emotional support was the most needed and matched coded category. A match was indicated by comments providing emotional support, or information that encourages one to feel or believe that they are cared for, loved, valued, and that they belong. It emphasizes one's feelings and protects or helps one recover from "emotional losses" that occur as a result of a stressful event. The following thread exhibits a match overall due to the multiple responses providing emotional support. It is important to remember that individuals may still provide both forms of support, such as informational advice in addition to emotional messages.

OP(original poster): Please help me... I feel so useless. I don't think anyone likes me anymore. I try to make friends but it never works. I hate my voice, my body, everything about myself. I've gotten to the point where I think about killing myself... I really need someone

BrandonFlag: Don't do that, please! You're such a beautiful soul My Kik is brandonflag if you ever need to talk.

PajamaPants3: You are so beautiful, on the inside and the outside.

VirtuousWeirdo: I promise it gets better. EVERYONE struggles with self-esteem issues at you're age. It takes some time to learn to love yourself, but you're not alone there. I'm not even $100 \%$ happy with my appearance, so I get where you're coming from. We always see the small imperfections and inflate them and obsess over them and waste our days wishing we could change them. But it's pointless. Why should anyone's opinion influence you so much? They are irrelevant to your life. You have to learn to ignore negativity, get a thicker skin, and find an outlet for support (Like LGBTchat!). Don't ignore constructive criticism, you need to be able to tell the difference between that and bullying. I also have had suicidal thoughts frequently over my years, but it's all about willpower. If your think you can get through it, you can! The clouds always move away eventually and let the sun shine through. I would need more info to help your friend situation. None of this may have made any sense to you, but if you ever need to talk just click the link in my profile and I'll respond ASAP. You can always also call the Trevor Hotline at 1866-488-7386 too. Just don't forget that there are people here for you! 
Faded: I also don't consider myself god enough looking, yet I still found a partner who loves and cares for me, so I can't possibly be that bad! You will find someone you love too. I'm also 14, and at this age, it's difficult to build out self-esteem. But suicide still is not the answer because one day when you are older, you will find happiness and be glad you didn't end your life.

InvisibleMember: I agree with this thread and must stress that suicide is NOT the answer. I hate knowing that you had such thought and I want you to know that you have people around you that love you and care for you. They will be there for you and love you for who you are. If you are having difficulties finding friends, try joining a club or finding a hobby. When I younger, I took Martial Arts and met friends. Don't give up and keep talking to people, we are all here to help.

Shawn Suicide is not the answer. If you ever need someone to talk to, Kik me.

Muffler: There is nothing easy about being a teenager, I did my time and would not go back for anything. I was an easy target for bullies because of my size and acne. When I was in $7^{\text {th }}$ grade, I made friends with a math teacher who helped me out when bullies would mess with me. I bullied someone once and I hated myself for it.

Cherub71: Young boys have and will always hate the way their voices sound and how their bodies look, if they say otherwise, it is just a cover up, trust me, they are just as insecure on the inside.

When you are young, time seems to move very slowly, days seem like weeks and weeks, like months. Once you are older, you will look back on it and it will seem as if your life changed in a split second.

Join a group or club at school with people who share the same interests as you. You have to be patient but eventually you will make friends that share the same ideas and may be going through the same thing you are.

Continue to take to the people on this site, younger users like yourself can help each other. You should not feel alone here.

Emotional support is exhibited in these responses. The messages assuring the OP that they are a beautiful person on the inside and outside, that they are appreciated in the forum, that other people's opinions do not matter, and normalization of having selfesteem issues help to counteract the individual's negative self-perception. The responses that offer future communication if the individual ever needs someone to talk to promotes 
feelings of belonging and provides social companionship, which helps fill their socioemotional needs.

Through refinement of coding for emotional support, the response data presented multiple ways in which emotional support may function. Many of these forms mimic the buffer mechanisms discussed in the literature and presented by Cohen and Wills and Cohen and McKay. The emotional support mechanisms found in this data include esteem support, social companionship, reappraisal, and social comparison.

\section{Esteem Support}

Esteem support counterbalances threats to self-esteem by emphasizes one's evaluation and feelings about themselves or raising one's awareness of their self-efficacy to conquer their problem. In this study's context, this often took the form of reassuring the individuals depending on their situation in attempt to rebuild an OP's self-esteem. Esteem support was coded frequently because many of the issues experienced by the OP's resulted in feeling bad about themselves, especially if they are not accepted by their families for their sexual orientations or gender. Numerous OPs put themselves down and called themselves names like a "monster" or "worthless". Esteem support responses towards needs like this follow with comments in the style of compliments. Responders remind the OPs that they are worthwhile, appreciated, deserving, loved, beautiful, and strong and that people do care about them. The following example demonstrates esteem support at work for an OP who is experiencing internalized homophobia and putting themselves down:

OP: I have never opened up about my sexuality to anyone; honestly, I'm not even comfortable with it myself. I know there is nothing wrong with who I am, but some 
days I feel like a freak just for loving someone. I tried reaching out to someone about my sexuality but instead of helpful advice, he threatened to expose me and before he could, I wanted to take my own life to avoid having to face the reality of everyone knowing. I was so afraid of people finding out and not accepting me.

Mateo: Don't consider yourself a "freak". From my experiences, putting yourself down only makes matters worse. You have value and purpose in life and you shouldn't end it because of who you are. Things will start to look up for you and they only way to reduce the possibility of thing getting better is suicide. Coming out to other people can be very difficult and you must be strong. It is a small chapter in your life and 20 years down the road, it will just be a small bump in the road that you overcame. You cannot let other people's opinions define who you are. At the end of the day, their opinion does not matter and it should not determine your happiness.

YoungPanKid: Nobody can take away your true beauty and you will have that with you forever.

BubbaGumpBoy: ... Everybody views people differently and just because one person sees you one way does not mean everybody will. You are strong! Take the opportunity to explore yourself and make yourself happy. Remember, you are special. Love yourself because you are different! $<3$

PSherman42: Everyone's advice has been pretty good. I'll just add that, yes it is ok and you will be ok. In time you will learn to accept yourself and find confidence.

The responders, like Mateo, specifically address the OP's low self-esteem issues by reassuring them that they are not a "freak," and that it is okay to be gay. Others like BubbaGumpBoy also promote self-esteem by reminding the OP that they are special, and strong, as well as encouraging self-love. These comments provide a match for the OP's need for emotional support.

\section{Social Companionship}

Social companionship reduces stress by meeting one's need for a sense of belonging, distracting one from their stress issues, or facilitating a positive mood by virtue of companionship. The individuals online are not able to provide physical 
companionship, but they still demonstrate the ability to facilitate a sense of belonging.

This was observed in the form of reassuring that they and others in the forum are there

for the OP, that they are not alone, as well as inviting them to reach out to them anytime

they wanted to talk or needed someone to be there for them. This may or may not result

in private conversations between them in the future, but the offer is on the table. An

example of matched responses using social companionship follows (phrases indicating

companionship are underlined):

OP: I've been attending church since I was 17, and well here it goes... I realized I was different, that I liked girls instead of boys since I was about 7 or 8 . I never said it out loud, just suppressed it because other gay kids at school were bullied and I didn't wanna get made fun of. I felt so lonely and unwanted and hid behind humor. Then I fell in love with church, but I still had the same lonely feelings. I have wanted to kill myself a few times now. I just don't understand why the church hates homosexuality if I was born this way. I really need a friend to help me and be there for me and accept me. I'm in such a dark place right now and don't know how to get out. I just don't want to feel alone anymore

PowerPuffGirlX : Sending you hugs! It really is tough growing up in a religious community. But your sexuality is what makes you YOU, its not bad! You're perfect just like you are. I can be your new friend, I'm usually always online so feel free to message me anytime.

Beautiful_Dawn: ... Just DM me and I'll always respond ASAP. I'm here for you always!

JerryGarcia: If you want, I'll be your friend!

SupaSweet: It's going to take some time to accept this. But anytime you need someone, I'm always online! You can always message me."

May92: Message me anytime, you are not alone. 
These responders recognize the OP's need for companionship due to the expressed loneliness and offer to fill this need by volunteering to be the OP's friend, offering support for future reference, as well as assuring them that they are not alone

\section{Reappraisal}

Reappraisal was also used frequently in order to alter the way an OP viewed their situation or identity, and persuade them to not act on their ideations. The following example thread shows reappraisal used to change the way an OP thinks about their identity in order to address an OP's internalized homophobia:

OP: I'm so tired of being stressed about what I am not being what I want to be. The pressure, guilt and frustrations with being gay. I think about death more than living. My parents know and they don't have a problem with it, but I still want to end my life. It's just not something I can live with. I don't think it's that I want to die necessarily, I just don't want to be gay. I want to be free and I don't know how much longer I can handle it.

TheHomoDragon: You're sexuality does not define you as a person, it's just one part of yourself. So you're gay... so what? That doesn't change anything about you. You are still the same you and you don't have to change who that is. Being gay doesn't mean that you have to act or dress "gay". YOU define the label. All it means is that you like people of the same gender as you. You don't have to parade it around if you don't want to because, again, it's not the most important or biggest part about your personality or identity. Some people do, but that's their choice too. There's not even that big of a difference between straight, gay or bi. Just who we are physically attracted to and we all have to live with how we were created. Life is too short to be anything but happy and to wish we were someone other than who we are. And if you push through the hard times and the pain subsides, you'll be so wise. By staying alive for your future, you have the potential to help so many people going through the exact same thing as you right now. If you can't find a reason to keep living, then there's really no legitimate reason to die either...

Bboy98: If you look hard enough you can find the beauty of this world. There are going to be people going through the same stuff as you and they're going to need people like you who pulled through it to give them hope. Hang in there! 
TheHomoDragon uses reappraisal support in attempt to change the way the OP thinks about being gay. They put the power back into the OP's hands by reminding them that they define their identity, not a label, and that their sexual orientation is just one aspect of their identity. In the same comment, TheHomoDragon also uses reappraisal to reframe the way they think about their future, which is only possible if they do not kill themselves. Bboy98 similarly uses a future-oriented reappraisal in order to open their mind to the important role they could play in helping others going through the same things if they stay alive. These future-oriented and empathy-inducing reappraisal tactics were common throughout the threads as a way to not only change the way OPs think about themselves and their circumstances, but also about the concept of suicide as an option. Reminding suicidal OPs of reasons to live, hope for their future, and all the possibilities to come if they push through the hard times was a common tactic of reframing.

\section{Condemning}

Another form of reappraisal that was observed in these sample threads was that of condemning an OP for considering suicide. Condemning comments are considered a form of reappraisal because they attempt to reframe the way the OP thinks about suicide as an option to solve their problems. These condemning comments were largely just stated opinions about suicide as being a selfish or cowardly act, but they also sometimes included harsh personal attacks and name calling. A list of examples of these condemning comments are provided:

Conspirtor001: So you want to die...okay... what would be the result? Some will cry, some will be sad, some will miss you. You will regret it after. You're being a pussy by letting your sexuality define you. I have no friends and my dad considers me a failure deep down and I live in a homophobic country. Do you think you're 
the only one going through this? Get a life. You should be proud to be gay. You get to play games and have an upgraded best friend as a boyfriend. You want to miss out on that?

Conspirtor001: I said this to help you. Aggressive post are more likely to help anyways but I guess I'm sorry it offended you. I can't help you if you thing think being gay dictates masculinity. You're just making excuses at that point. I have so many reasons to give up but I don't, I can't really help you otherwise. You will regret it later.

5Lives: A lot of people believe that suicide is a cowardly decision and way to die and that it's selfish. I agree with these people. It's awful and is the ultimate reflection of selfishness because it affects everyone around you and no one ever forgets.

BrikSquad: I have no pity for people who are so self-absorbed to commit suicide. They don't deserve life, and it's the truth, I'm sorry. There is always a solution.

These examples of condemning comments also demonstrate that the negativity is not purely to hurt the OP, but to also remind them how their suicide will affect others, especially their families and loved ones. This functions as a reappraisal by shifting their thoughts outside of themselves, which is similar to the future oriented and empathyinducing examples from above.

Another point to note is that reappraisals did not commonly occur by themselves, but were used alongside other mechanisms to strengthen their point. They were often followed by advice, for example. Reappraisal techniques are used by professional counselors and therapists and are a good way to permanently help an individual with poor self-images or help give them the skills to find solutions for themselves in the future. 


\section{Social Comparison}

Social comparison was the most commonly used form of social support offered in the forum for suicidal OPs. This was the responders' way of relating to the OP and showing them that they are not alone in their experiences. Social comparison is also a way to show OPs that their situation will eventually get better. This is done by responders sharing personal stories of experience with previous suicidal ideations and how life did get better for them. This helps shift their feelings away from hopelessness and inspire OPs to look forward to what is in store for them in life. This use of social comparison can function similarly to reappraisal. The two forms of emotional support were sometime seen used at the same time when responders referred to examples of people they know who attempted or almost attempted suicide as a social comparison rather than their own experience. See the following example of how social comparison and reappraisal work together in the same comment:

OP: Does anyone else ever think of suicide???_Sometimes I do....is that bad ?? people will probably forget about me anyways.. Damnit I'm just so depressed.....

Zeke: Yes, very frequently, sometimes multiple times a day for months on end. Though I don't has much as I used to anymore, it still crosses my mind every so often but more as a fleeting thought. It's more of a reminder than an urge like it used to be. It's taken a lot of time and energy to shift my mindset to where it is now and I hope to continue on that path.

You need to know that this isn't your fault. Problems with feeling suicidal can be genetic, come from trauma from your childhood or toxic relationships, society stigmatizing you, or even sensitivity to food or blood sugar problems! For me, all of those things contributed to my expense with feeling suicidal. I just had to figure it all out through research and learning to manage it through trial and error. Again, this isn't your fault. You are not weak, it's just a symptom of something you are lacking in order to thrive. And what you are lacking can be discovered! It may just take time and determination. 
Remember- it is ok to reach out for help. The fact that you are posting here and asking for opinions is a great sign. There are plenty of avenues for support out there, you just have to be willing to look for it and ask for help.

Here Zeke refers to his mother's coworker who experienced a failed suicide attempt and because he was given a chance at life, he went on to become a life saver and impact others in need. This compares to similar others as well as provides a future-oriented reframing.

Social Comparison is also used as a means of normalizing an OP's feelings since many LGBTQ individuals experience similar stressful events, such as coming out and not being accepted. Messages communicating comparison often presented personal details, disclosures, and stories of their own experiences. Social comparisons were also commonly used even when they were not requested by the OP and also mostly appeared at the beginning of a comment with other forms of support following.

\section{Sympathy and Understanding}

There were also other emotional responses observed that were not previously categorized in the literature discussed in the theoretical framework. These responses included messages communicating understanding and sympathy. Comments conveying understanding are communicated similar to active listening in a face-to-face conversation. It lets the help-seeker know that someone read and fully understood their situation and where their feelings are coming from. This can take the form of rephrasing what the OP is going through and validating that they understand the gravity of the situation for them or translating what they understand about the individual's feelings or situation in other terms. One example of this can be "I know this situation is very hard 
for you to deal with," or "I understand that you are hurting right now, but suicide is not the answer." This was sometimes hard to distinguish from social comparisons in which people said they understand how the other person feels because they have experienced something similar. However, comparison comes from a place of empathy and relating. Sympathy often used when responders could not personally relate, but felt sad for the $\mathrm{OP}$ and their situation. Therefore, it was used in place of social comparison, which was normally the initial response to numerous posts. This usually appeared in phrases including apologies such as "I'm really sorry you are going through this" or "I'm so sorry you are feeling that way.”

\section{Informational Support}

Informational support was the least needed and matched coded category. This is mostly due to the fact that the suicidal OPs are dealing with emotional issues stemming from their personal situations that are causing them to experience suicidal ideations. Therefore, more posts were soliciting emotional support. There were, however, nine threads conveying informational needs. Informational support contributes to an OP's body of knowledge. This took the form of providing facts, advice giving, or making referrals. Informational support, especially advice, was often provided even when it was not specifically asked for, but information support matches only occurred when an OP specifically asked for advice or information.

Advice

Advice giving seeks to provide solutions to a problem and was a common use of informational social support observed in the sample threads. Advice providing matches 
for informational support were usually focused on OPs' external situations causing their suicidal feelings. These advising comments varied depending on the OP's specific situation. Advice on coming out, for example, was often requested and resulted in advice such as writing a letter or having someone with them when they come out to their families to further ensure their safety. The following thread provides an informational match utilizing advice giving for the OP's external situation:

OP: I posted here a month or so ago about telling my mom about my suicidal thoughts, but I never did and it has gotten worse. My parents and I fight even more, I'm more depressed, really want to die. I am also self-harming and don't have feel like I can tell my parents. I plan to tell my counselor at school tomorrow but I have terrible social anxiety and don't know how. In Florida where I live there is a law called the Baker Act where if a minor especially is suspected of being at risk for harming themselves or others you have to report them. Then I could be taken to get treatment and the hospital decides what to do. I feel like this is the best option so I don't have to tell my parents and I really need help. How can I tell my counselor? I really need advice.

WastedShroom: There are lots of people here who will give you advice and support you. I suggest writing all of this down in a letter and giving it to your counselor. That may be easier for you.

WastedShroom: I am so glad to hear from you! We were so worried because we didn't know what happened to you. I agree, write it on paper and give them the note. Tell them you are suicidal and don't know what to do so you're seeking help. They will know what to do. I hope you get to feeling better!

Cherub71: Yay Oliv3r! I have been so worried about you. I think this advice is excellent. Just say you are depressed, have been self-harming and are suicidal. You could even leave it with a teacher that you know cares in a classroom as you leave. When they call you to the office, you are free to break down. Just make sure that they know that you know about the Baker Act. This was a great idea for getting yourself help, now just act on it. :)

Muffler: This may sound crazy, but adopting a dog could save you!

Beautiful_Dawn: Brother, I am so sorry you are going through this. The Baker Act is a great idea and I almost did that myself one time. Just write a short note and they will help you. We will be praying for you. 
In this example, advice on how communicate with the OP's school counselor about his suicidal ideations was specifically asked for, and matched overall. The consensus from the responders was to write it down and give her the note or letter, which provides a solution to the OP's issues with social anxiety and allows them to reach out for the help they need.

The next example demonstrates an informational match for an OP needing help coming out to their family as transgender in order to begin transitioning and avoid more dysphoria:

OP: My dysphoria has gotten so much worse lately that I have been really suicidal. I need to transition already before it gets worse. I have already reached out to some gender therapists, but money is an issue. I'm terrified of never being able to start T, and being trapped as a female and that my family won't accept me if I come out. I don't want to lose them. I would be grateful for some pointers or advice.

ShoeLover: I have yet to transition or come out, but ill still try to give good advice based on my research. First, if money is an issue, you kinda need your parents help to transition. But if you think it would be unsafe to come out, then you should probably wait, for your safety. Maybe try coming out in a written letter and have resources on trans stuff to help them understand. Its less confrontational and you can make sure to say everything you want. You could also test them about how they feel about trans people by bringing up the subject with movies about it and asking their opinion. Sorry if that didn't help, but good luck! I'm here if you need to talk

Beautiful_Dawn: ... You have to learn to look passed your appearance and see what inside, like I did. Stand in the mirror and see it. If you can do this you will always see yourself staring back. You will be happier less anxious. There are some states that have funds for transgender medical care, you just have to jump through hoops to get it...

Volvomin: ... If you think they will react physically, then for your safety, I would try a letter instead and stay at a friend's house. If they are supportive, then I would ask for financial support for transitioning...

Jason Joshua: ...I suggest using someone else as an example, like Caitlin Jenner. Use her experience to express how you feel as a transgender person. It would give 
you the safety to test the waters about how open they are to the idea in case they respond badly...

In this example, responders have the OP's safety in mind when formulating their advice. They suggest methods of avoiding confrontation such as writing their parents a letter, or testing the waters by asking their parents how they feel about transgenderism in general. Beautiful_Dawn on the other hand, focused on advice for the OP's dysphoria as well as the financial barriers to their transitioning, which may help them avoid having to come out to their parents if they are not ready, or are rejected after coming out.

Responders were able to provide advice regardless of whether the topic was focused on external situational issues or internal emotional issues. Due to its applicability, advice was frequently offered, even if it was not requested. This was observed in threads eliciting emotional needs, however, advice used in this way did not provide a match. When aimed at emotionally charged posts, the advice usually occurred alongside emotional forms of support such as esteem support. Advice in relation to esteem support was focused on action the individual could take to make a change for themselves and how they feel. This advice focused on their internal issues and suggested alternative means of coping. Examples of advice centered around the phenomenological phenomena included "think more positively," or suggested meditation. Responders also frequently advised the OP's to learn to love and embrace themselves rather than looking for it from others, as well as finding a hobby, doing something they enjoy, or focusing on things that make them happy when they are upset. Other responders offered more specific coping techniques such as writing on your arm or snapping yourself with a rubber band to avoid cutting and self-harming, which is a common issue among forum members. More 
common advice for managing suicidal ideations and feeling better frequently included suggesting that they seek therapy and continue reaching out to the forum and other resources for help. This was also seen in the form of giving referrals.

Referrals

Informational support provided to OPs who were seeking help with an external situation also included giving referrals and information. Referrals were made to crisis hotlines, such as the Trevor Project and the Trans Lifeline, to websites that could help an OP find professional therapists who specialize in LGBTQ and gender issues or to local LGBTQ resources, or suggestions to songs and music video attachments in order to help inspire or brighten the OP's mood. These were often made through social comparison because they are songs that personally helped the responder through hard times. When specific referrals were given, they were often utilized by the OP and action was taken. In this next example, one OP named Bumblebeez, was provided a couple of links to websites listing local resources for transgender health and services in order to help them find a gender therapist specifically. Bumblebeez immediately made an appointment and planned to make more to compare therapists. Ten days later they came back to update the responders that their first appointment went wonderfully and better than they could have hoped for. The outcomes of the therapy appointments were provided as well as communicated feeling happy and hopeful. This is a good example of a matched thread that includes referrals:

OP: Apologizing now for the long post, but I've dealt with this alone for a long time and it's time to let it out. An anonymous forum is the best place to do so I think. I've had conflict over my gender since kindergarten. I've never had guy friends. I have memories from my whole childhood that tell me I'm supposed to be 
a girl. My mom told me to suck it up and deal with it when I told her how I felt. So I did. My journals through high school tell every time I felt like killing, hurting, or mutilating myself. It had drafts of suicide notes and one final copy. The only reason it was never used was because my mom told me that if ever did something like that it would devastate her. I didn't want to hurt her. I have now been with my wife for 14 years and we have a daughter. I have a good career. But I still wake up not feeling right. I still have regular thoughts of suicide and no one in my life has any idea that I feel like a woman. I'd really love therapy, even if I never transition, but I don't know where to begin. Would anyone accept me? Would I be able to continue my job as an elementary school teacher? I'm not sure where this is going anymore, but I'm hoping just posting it will help. Thanks.

AgriculutralSir: Maybe you should see a gender therapist in secret. Your partner may wonder where you are going, but you could make something up or say that you're going to going to normal therapy, but she'd still be curious I'm sure. But this is just a suggestion. Feel better!

OP: Thanks you for the advice. Do you know how I can find a gender therapist? Would it require a referral from my primary physician?

KTSoars: Where area do you live in? you should try looking into local or national charities to start with

OP: I live around the DC area.

KTSoars: Try this link: https://dctranscoalition.wordpress.com/resources/transhealth-and-services-in-dc/

OP: Thanks! I picked out a couple therapists and emailed them. I don't have an appointment as of yet. I'm pretty nervous about telling a real-life human all these things. It's terrifying, but I gotta get busy living or keep being busy dying, like Andy Dufresne said. I've spent too much time dying.

RED: This site has a more extensive search option and on the left you can pick a criteria like transgender to find one that is specialized in gender. (hyperlinked to $\underline{\text { therapist) }}$

OP: Thanks for the link. I just emailed two more therapists. I'm going to see who I click with, if any.

PortlandPatty: you should check out DrBecky.com too. It's a site that specifically shows therapists who are knowledgeable about transgender issues. There are therapists in most states, and I'm sure there are several in the D.C. area. Just be careful, many psychologists know little about transgender-specific problems. These 
people are fine for general concerns, but we are special. One counselor told me that the only transgender education she had was covered in one morning. And certainly anyone that is a religious counselor should be avoided.

OP: I'll definitely keep all of this in mind and avoid Christian therapists. I'm a closeted atheist as well and definitely want to avoid being preached to. In fact I'm betting that it has a lot to do with the issues I have now.

KTSoar: That's so awesome! Seeking counseling is a scary first step, but just remember that they meet people with all sorts of problems and they do this job because they are passionate about it. It doesn't exactly pay very well anyways. Also, if the counselor you see isn't actually very experienced with gender, they may be able to refer you to someone who is! Good luck!

OP: I made my first appointment with for this Thursday and am working on a second for Friday, so that I can compare them. I hope it goes well, but she sounds like she really knows about this stuff, like helping people transition, so I'm pretty sure I won't get preached at.

OP(10 days apart): My first appointment went wonderfully! She gave me lots to read, validated all of my feelings and even discussed a possible route to transitioning. It went so much better than I could have imagined. Just one session, and I already feel closer to being ready to come out to some sympathetic family members.

Junior: Be true to yourself and accept your femininity. You need to be honest with your wife about how you've always felt this way. But lead up to it. She needs to know. It's going to be hard, but I think you will be happier in the end.

Both Needs

In threads demonstrating a need for both emotional and informational needs, responders were still able to provide matched support to help-seeking OPs. All 12 threads in this category were matched for both needs. This is mainly due to the ability of responders to provide multiple buffer mechanisms in one comment. Responders also build off of each other's comments to figure out how they should respond in order to have all of the OP's needs met. This is indicated when some responders focus on only one part of the OP's needs after another responder has already addressed another need. 
The following thread is an example of a match for both needs. Both needs are conveyed through the OP's expression of asking for help with coping with their fears of living in a homophobic country (informational), and the unaccepting community and family they live among (emotional).

OP: I apologize for any spelling errors because English is not my first language. I'm afraid to do this, but I suppose I can be honest here. My problem is that I live in Russia, which is really homophobic. I will never have support from my family or mother. It seems impossible, life a fairy tale. This is so unbearable that I am considering suicide. I'm positive I'll be treated like an animal if they know, and there already rumors that I am a lesbian going around school. There is now a law against gay propaganda here so pride parades are banned now. My mom was watching a news story about gays in Europe and talked about how fucked up it is and that the Bible says it's a sin. I just cried by myself in the bathroom. I meet with a secret LGBTQIA+ group once a moth and I feel safe there, but people yell at us and call us 'fags' and say we're ruining their culture. I'm so afraid of living here, afraid of existence. I know a boy who was raped for getting caught kissing a boy. I'm not able to move and don't know how to hope. Someone. Please help you. I can't stop thinking about death.

Emilia: I'm pretty sure you could move due to being persecuted for your sexuality.

OP: I'm still too you to move and have to finish my studies here. I don't know if I'll be able to afford to after I finish uni either

Emilia: Refugees don't have an age restriction. But you're parents are still responsible for you if you're under 18. But if you're in danger there they shouldn't hold you hostage if you want to leave.

OP: At least they don't abuse me physically. My mom and I have a complicated relationship, but we love each other. But I know she would still kick me out if came out. I'm going to have to wait until I'm 18 to move out.

Librarian: That's a really sad story. Like Emilia said, move to another EU country. But I know that's easier said than done. We're here for you.

OP: Thank so much for caring. It means so much to me $<3$

Cherub71: I feel like Moscow or St. Petersburg would be better for LGBT people than small towns because there's intellectuals and less Church influence. Maybe if 
you go to a large uni, you could meet supportive people. If you're concerned about staying anonymous or want to get around censorship look here: https://www.torproject.org/

Beautiful_Dawn: I hope things work out just remember we are here for you any time you need to talk.

OP: I live in St.Petersburg now, but I used to live in the small. There is one LGBTQ-friendly cafe, but I'm not sure it's legal. If I feel unsafe here, I can't imagine how LGBTQ+ people are surviving in small towns. Thanks for the support. It means everything to me.

$@$ Beautiful_dawn thanks a bunch $<3$ to be honest, I've never heard words like this from anyone before. Love you.

SandyDee: I advise you to be super careful about what you're saying online. My partner works for the government so I'm familiar with algorithms that the Russian gov. and agencies use to monitor its citizen's online activity. Keywords get flagged, so don't be too critical of the government here. Your situation is horrible and not likely to get any better in the future. But, you are young and you have time. I suggest you start planning for your future for saving money and setting goals to move. In the meantime, stay silent. Your life fay depend on it.

Faded: I think need to wait till you're 18 to move away. Since you know English you could move to an English speaking country. I think you may have to stay closeted until you have a safer environment too. If someone accuses you of being a gay, deny it. I know all of this sounds hard but it's for your safety Suicide is never the answer.

Emilia: You can get around in a few other ways like using TOR or a couple proxies. A public computer could help too, but make sure they don't track who uses them

SandyDee: True, I'm just concerned that this young person understand how careful they must be...

Beautiful_Dawn: I never received support like this either until I came to this site. So I know how you feel. We are here for you!!!

OP: thank you everyone for caring. My computer is broken, so I just use another one. I do know about TOR and I had these apps that allow me to change my location and

proxy.

Emilia: If you are only using 1 proxy, it's still easy to track you. (Not trying to scare you) 
DarkPowerfulCheetah: I'm so sorry about your situation. I know enough about Russia to understand the peril that you feel and the peril that you are in. It becomes much easier to be alive when you're an adult, when you know you can survive on your own. Right now you are dependent on others. Hold on until you are older to feel stable on your own. Leaving your family means that you love yourself. Your current situation will never bring you happiness. Nothing will get better until you realize you have the power change it.

Bella: I'm so sorry about your situation. It sounds super scary and I can't imagine living like that. Research ways to legally leave the country and find safety. I've also been in situations where I felt like suicide was the answer, but I promise it will get better. We are all here for you. You can do it! Stay safe <3

Multiple responders in this thread example suggest that the OP try to, or begin planning to leave the homophobic country since they are concerned for their safety. Such suggestions are advice which matches the informational need. Information and referrals are also offered about how to become a political refugee as well as how to discuss these matters safely over the internet due to Russia's censorship laws. Others, like Faded, suggest waiting until the OP is 18 to try moving elsewhere as well as staying closeted and silent about their orientation in the mean time for their safety. In order to meet the OP's emotional needs, responders offer companionship and sympathy. The emotional needs matches are validated through the OP's comments expressing that they are grateful for the support and that they had never heard nice and supportive words from anyone before they had made the thread on the site. The comments between SandyDee and Emilia demonstrate how responders consider each other's responses when providing advice in order to assure that the $\mathrm{OP}$ is receiving proper support and information. 


\section{Perceived Support}

Cohen and McKay explain that perceived social support is more important than the support actually provided. However, in this study, validation of perceived support was not always provided by OPs, and therefore, could not be used as the sole indicator of support responses creating a stress-buffering effect. However, when the perception of feeling supported and belonging to the online community is communicated, it supports the conclusion of support responses being helpful in buffering stress depending on matches. For example, revisit the validating responses provided by the Russian OP from the previous example.

OP: Thanks so much for support, it is very much appreciated. It means so much to me.

OP: I can't find better words to say than just simply 'thank you.' It's just so important to me. Until I made this thread here I had never felt supported like this by others.

OP: Thank you so very much. It helps me a lot.

The assertion that the OP had never felt supported for their sexual identity before is striking, but assures that the social support provided by responders allowed a buffer in the OP's stress. These validating responses not only exemplify validation of support, but also shows that the forum is indeed helpful to those seeking help and social support.

There was evidence that some of the responders successfully helped an OP avoid a suicide attempt, which is the outcome that is hoped for in the stress-buffering intervention process in this study. The following message from an OP is an update to follow up with the responders:

... I'm working on getting over using self-harm. Don't get me wrong, I have scissors and such in my room and they are tempting. It's an addiction that helps me release the stress. But like heroin, it takes time to fully get over that temptation. 
And don't worry, I'm not going to "murder myself" because it's not what I want anymore. Honestly, my girlfriend keeps me from committing because she is a selfharmer too and I know she would kill herself if I did. Plus now I have all of you here in the forum to support me through this. I'm beyond grateful to you all because without your support, I wouldn't still be here. When I read through these comments, I smile. They make me realize that I can push through all of this and make it to adulthood and hopefully find a stable environment where I can be with my girlfriend. Thanks again for all the support $<3$

In addition, there were comments providing validation that some OPs took the advice from the responders and acted on them leaving them with favorable results. Consider the example of OP Bumblbeez from the referral section. Bumblebeez took the advice given and validated it as helpful. The outcomes of the therapy appointments were provided as well as communicated feeling happy and hopeful. This evidence validates how helpful these support responses were in buffering stress even further.

\section{UNMATCHED RESPONSES}

Though all of the sample threads were evaluated overall as being matched, not every individual comment provided matches. Although the unmatched comments did not hinder the ability of the thread as a whole to provide a match, it is important to note that not all responders provide support equally. Some responders miss the mark, while others hit the target. Comments were unmatched, for example, if they provided only informational support to a thread post conveying emotional needs, and vice versa. Here is an example of an unmatched comment due to the responder providing only emotional support when the OP needed informational:

OP: I've never attempted suicide, I'm too rational. But I'm so mad that I imagine slitting my wrists. I direct my anger inward to stop from hurting other people. But, 
the thing is I live in a facility with emotionally abusive staff. She is so abrasive and critical she makes me want to cry and harm. And I can't prove it because DCF doesn't investigate without proof. At work I am not respected and hear homophobic remarks constantly. I'm just some autistic artist guy. I'm not taken seriously, but like a nuisance, they don't respect my intelligence. I need to escape this system to be healthy, but I don't know how. I was declared incompetent to live on my own, but I need out. I want to go to college, work and love alone. I don't even know what court my case is in or how to get an appointment. Please help

TechnicallyStephanie: I am so sorry that you are going through that, it makes me sick to hear this. I wish I could help you from here, if I could I would.

Comments were also unmatched if they provided no support, such as in the case of irrelevant comments. The following example shows an irrelevant comment that does not address anything about the OP post or issues. It offers nothing constructive and does not provide any type of support:

Muffler: I am too tired to rant about things

These irrelevant comments were not as common as matched comments providing social support, which is evidenced by the overwhelming matched threads and lack of unmatched threads. 


\section{Chapter 6. Discussion}

This chapter further discusses and analyzes the findings presented in the last chapter. It will also describe issues encountered during the process of coding and analyzing the thread data according to the stress-buffering framework. As a result of these issues, other emerged themes found will be described. Lastly, a critique of the stress-buffering model and what it means for qualitative research is provided.

\section{DISCUSSION OF RESULTS BY SUPPORT CATEGORY}

The results of this qualitative content analysis of LGBTchat.net showed that 100 percent of the OP's needs, as communicated in their posts, were matched by the social support messages provided by responders in the forum. According to the stress-buffering framework, this provides overwhelming evidence of the buffering hypothesis at work as well as evidence that suicidal individuals are receiving proper forms of social support on this website. Due to this conclusion, it can be argued that LGBTchat.net has potential to be a valuable source of social support for suicidal LGBTQ individuals to turn to.

\section{Emotional Support}

Emotional support was needed (and matched) the most compared to informational support and those needing both. In this support category, buffer mechanisms described by Cohen and Wills and Cohen and McKay were identified within the variation of emotional support. Esteem support was very common in these threads due to the loss of self-esteem commonly presented by OP's in their threads. The common appearance of esteem 
support can be explained by the ease in which it is to offer it in virtual interactions because it generally takes the form of complimenting.

Social companionship was also commonly provided due to the frequently expressed issue of loneliness and isolation as an LGBTQ individual. Social companionship rarely ever occurred alone, and was more commonly observed supplementing other forms of support messages, indicating that responders wanted to assure OP's that support was there for them in the forum, especially for future reference.

In addition, social comparison can supplement companionship because it strengthens feelings of belonging and shows an OP that they are not alone in their circumstances since others can relate. Due to its supplemental nature, social comparison was the most commonly observed variation of support used in all three need categories (emotional, informational, and multiple needs). The high occurrence of social comparison in every support need category shows how the common issue themes brings this community together in this online forum and that these negative experiences and suicidal ideations are common to this population. Even if a responder does not have any other means of offering support, they can at least normalize these ideations for an OP and show them they are not as alone as they think they are.

Reappraisal was also commonly seen applied to a range of different issues and supplemented other variations of the two support categories. When aimed towards the concept of suicide, reappraisals discussed it as a limiting option that does not end pain, but passes it on to others, and ends all possibilities of change for a better future. This sometimes had negative connotations and took the form of condemning OP's for their 
ideations or for considering suicide as an option to their problems. However, these condemning reappraisals were risky attempts at preventing suicidal behaviors on the OP's ideations due to the negative put-downs included in them. Reappraisals (not the condemning form) are often used in therapeutic practice in order to shift the thought process in patients, and therefore, change their behavior. Therefore, the use of reappraisal found in this forum is a positive finding.

Lastly, the uses of sympathy and understanding by responders, especially if seen used by themselves, indicates that even if responders do not know how to fully provide support, they still want to show that they care. Conveying an understanding of the OP's situation simulates social support in face-to-face conversations and lets the OP know that they were paying attention to them. Sympathy simply functions to let the OP know that they read their post and cared enough to comment, even if they had no solutions or deeper emotional supports to offer.

\section{Informational Support}

The threads needing informational support to be matched were the smallest need category. This smaller occurrence is not only due to most of the issues presented by the suicidal individuals being emotionally charged, but also because of the ease in which responders were able to match informational needs with informational support. Informational threads were provided less responses in general because once advice is given, there is not much else that needs to be said. The majority of the threads eliciting informational support directly asked for advice, which eliminated the guessing game for responders in evaluating OP. It is, therefore, easy to provide a match for advice. Advice 
was provided frequently across all need categories due to the ability to provide advice for any scenario or issue the OPs were facing. For example, advice was observed most frequently in the emotional needs category, even though it was not requested by OPs there. The high frequency of advice giving also indicates that responders wish to truly improve an OP's situation in real life rather than easing their stress temporarily.

Informational matched threads provided further evidence that responders do not just consider the OP's post when formulating responses. They also read and respond according to the comments already given by other responders. This was demonstrated through phrases like "I agree with what__said," or "Yes, _ gave good advice." It was also inferred by later responders in a thread giving different pieces of advice by building off of what others had said or by not being redundant. Sometimes responders even discussed the advice among each other to make sure that the OP was receiving the best advice. These observations also support the inference that responders truly wish to help an OP's situation.

Referrals were also provided to OPs in order to match informational needs. These referrals to sources outside of the forum indicate that responders evaluate OP situations as outside of their ability to help and that more professional services are needed. Referrals were especially helpful for bringing solutions to OPs because the OPs frequently used the referrals to seek further help.

\section{Both Needs}

The support provided to OPs eliciting both emotional and informational needs showcase the multiple ways in which buffer mechanisms are used together by responders, 
rather than singularly, in order to meet all of their needs. Sentiments of companionship were often used at the end of a comment that first used informational support as a way to end the comment. This use of companionship shows that even when they have already addressed an OP's need, responders still wanted to create feelings of belonging and the availability of continued support, rather than offering support and then leaving them alone. Social comparisons also helped back up other forms of informational advice because responders could say what worked for them in their own similar situation rather than offering it blindly. The multiple needs category was more variable in the mechanisms employed. The most frequently provided emotional mechanism was social companionship and the other variations were observed far less frequently. This stark contrast may indicate that because there are multiple needs conveyed, it may be easier to just let the OP know that they have support due to being overwhelmed or confused.

When a responder is presented with multiple needs, formulating a response that meets all of the needs may be difficult. It is also plausible that responders are aware that they are limited in the extent to which they are able to help an OP through an online message. If a responder is aware of this fact, then they may have found it appropriate to just remind the OP that they have a community to turn to when more problems occur, since they are likely to due to the commonly recorded issues in this category including family rejection, depression, and identity concealment. Threads eliciting both emotional and informational needs also contained the most uses of reappraisals. This observation may be because there are needs presented that cannot be changed by a responder online, especially if there were multiple. If responders cannot directly impact a change for the 
OP's situation, they can still change the way the OP thinks about their situation and help them evaluate it as less stressful, or even motivate them to take action from pieces of advice. There was also lots of advice-giving observed in the multiple needs category, again due to the applicability of advice to any type of need or situation. High frequencies of advice-giving are also attributed to the many situations in each thread.

\section{Perceived Validation}

Though Cohen and McKay stress the importance of perceived support as a stressbuffering mechanism, in a virtual world of written conversations, evidence of this validation relies on the OP to respond in specific ways. Such validating responses may or may not appear, which muddies the waters of analysis in multiple ways. First, the OP may never respond back, and they often did not, which leaves the readers wondering if they are still alive, but also if responses were helpful. If they do respond with validation of perceived support by the end of the thread, it may be because they are trying to be nice or even act like they feel better as a result of receiving responses. This possibility provides the reasoning behind why helpfulness and evidence of stress-buffering was deciphered only through matches between needs and support. Perceived support only serves as supporting evidence of a needs match, and buffer in stress, and is not used as the sole basis of conclusion. However, matches that were validated by OPs as perceivably helpful, as well as instances where advice was taken and acted on by OPs does back up the finding of evidence of stress-buffering for the suicidal individuals found in this forum in all threads due to matches. 


\section{ANALYTIC ISSUES ENCOUNTERED}

The results discussed thus far have shown that these suicidal LGBTQ individuals are indeed finding helpful social support from this online forum due to evidence of the buffering hypothesis at work, meaning that LGBTchat.net has potential to be a great source of continued support for them. However, this finding is only contingent on the fact that support response type matched the need conveyed by the OPs. This conclusion does not show the full story of what is involved in the forum responses or what else was to be found there.

The simplistic conceptualization of "helpfulness" as contingent on matches guided by the stress-buffering model is the root of many issues encountered through the coding and analyzing process. The concept of social support found in the forum as being considered helpful was determined purely on whether a match is found within the thread overall. This conclusion does not account for the complexities and arbitrariness of human nature and social interactions, nor the limitations of them in online spaces, like LGBTchat.net. This ideal type of conceptualization of social support responses assumes that if the functioning buffer mechanism utilized in the responses matches the needs of an individual, then support is sufficiently provided and stress was successfully buffered. However, it does not actually evaluate or measure whether or not it was considered helpful to the OP subjectively. We can only know if it was helpful in a meaningful way if the OP responds with evidence of perceived support and validates that they felt supported, and this was not always provided. This analysis takes a subjective experience and attempts to judge its functions objectively. 
One issue that was encountered as a result of the match-based analysis was that it did not account for the support responses that did not result in a match, but may have actually been helpful to an OP in buffering their stress. These responses may not match the need that was specifically conveyed, but the responders considered them appropriate to provide, even if they were not what the OP was asking for or conveying a need for. The following thread examples show three different ways this may occur. The first example, exhibits how emotional support (reappraisal) is used to supplement advice when advice (informational support) is specifically requested. The second shows how informational support was provided when the need for emotional support was more apparent in the OP's post. The third shows how helping an OP reach the same goal of finding companionship can take different routes, by responders offering it themselves directly, or by suggesting ways to make friends in real life. Indicators for these points are underlined.

Example 1.

OP: I recently almost committed suicide and the only thing that saved me was a song. I have been really depressed about my gender identity. My best friend (who is gay) told me I should just be who I am and wait it out. I can't just settle on waiting. I think I am trans. If I think about it too much I get bad thoughts. I get excited when people mistake me for a male, but when I go to school, I look like a freak. I look like a dude but have to wear a skirt and blouse. Advice?

Beautiful_Dawn: It's really all just a matter of how you perceive yourself. Historically, a lot of men wore skirts such as the Scottish and Roman military. Just try to think of it like that. There's really nothing wrong with wearing a skirt, and you could even put a men's white undershirt under a men's white dress shirt. If you ever need to talk feel free to message me

Example 2. 
OP: I need serious help. I need conversion therapy. I have read a lot about it and that it has worked in some cases. Even though I am 13, I am certain of my sexuality. I have had girlfriends, but I hate myself for who I am. Please help.

Red: There are no credible psychological organizations that agree with conversion therapy, and some have even said that it is harmful

JerseySammy: Conversion therapy does not work and is illegal in some states. They are damaging, hurtful, and make people suicidal. You are not alone, love yourself!

Example 3.

OP: I don't want to be alone anymore and just want to give up. I want to be with someone close to my age.

Barefoot: Get out as much as possible and get involved with any LGBT groups available near you. If you don't know of any, ask around. Try and make as many friends as possible and stick with people physically near you, rather than resorting to online. Try and go where gay people go, like art galleries, plays, etc. Don't closet yourself any more than you feel that you must. Lastly, stay active in these things!

CoolNerd: I understand how you feel completely, but please don't give up! You can chat with me here or on Kik anytime. Keep fighting, I promise it'll get better!

In Example 2, the responders focused on persuading the adolescent not to pursue conversion therapy by providing them with information about conversion therapy rather than trying to help them think differently about their sexuality through esteem support or reappraisal. These responders decided it was more urgent of a matter and more helpful for the young person's safety and wellbeing to advise them against seeking the harmful therapy. Most would consider this helpful, but the matching analysis concluded them as unmatched, and therefore not helpful in buffering stress.

The last example also shows how various mechanisms can reach similar results or provide support in similar ways, but are not always coded as matched and helpful responses. This indicates that social support responses may function more intricately and 
apply more broadly than the theorists Cohen, McKay, and Wills believed. Social companionship and social comparison for example were observed to be used to reach the same goal of responders in helping the OP not feel alone in their circumstances, either by offering friendship or a shoulder to cry on, or normalizing their feelings or situation as commonly experienced by other LGBTQ individuals, which facilitates feelings of belonging to a group. It is difficult to decide which mechanisms are matching when there is more than one appropriate way of approaching certain issues.

In addition, mechanisms do not have to appear alone, more frequently than not, many responders actually utilize multiple buffer mechanisms within each response. This point also complicates analysis because some responders provide very well rounded responses using multiple mechanisms while others put little effort into theirs, but still provide the correct form of support. Both are coded as a match, but they are far from equal.

Zeke's response from the example used in the social comparison section of the results exemplifies a very well rounded and truly helpful response. Zeke clearly answered the question and call for social comparison, in addition to offering information about suicide. The OP also expressed feeling depressed that people would forget about her after she died. This need called for emotional support, like the esteem support provided by Zeke in reassuring that feeling suicidal is not her fault and that support is available. However, not every responder picks up on all of the needs conveyed by the OP and therefore, do not always provide support for all of their needs. Some comments only address one type of support requested by an OP. This variation in response style 
contributes to the fully matched thread needs and is caused by the process that responders go through when formulating responses. For example, if one very thorough response has already been given, the likelihood of more responses like that are slim because the need seems to have already been met.

Moreover, some advice was vague while other advice was specific and thoughtful. These differences could even be observed in comments within the same thread. For example, the two following pieces of advice were responses to an OPs request for advice on what to include in their letter to their mother for coming out as transgender:

1. Just tell how you feel inside.

2. Include what you feel is appropriate and be sure to properly explain everything. It is best not to rush things, so I wouldn't tell them your plans for transition in the future because it may overwhelm them all at once. But ultimately it is your decision to do what you think is best.

Of course, they both address the type of need requested by the OP, but one is clearly more thorough and thoughtful than the other. In order to gain a full understanding of the extent to which social support responses online are helping to buffer stress for suicidal individuals, it may be more appropriate to have a scale for deciphering the level to which a need is met in order to buffer stress rather than a dichotomous matched or unmatched decision. An example in social support literature that an adapted approach could be modeled after is Burleson's (1982) hierarchical coding scheme of person-centeredness, or the degree to which support messages reflect "an awareness of and adaptation to the affective, subjective, and relational aspects of communication contexts(Burleson 1987:305)". Perhaps more well-rounded responses that not only provide a match, but also supplement the match using various other forms of support should be considered more 
helpful because they show that time and effort was taken to formulate their support message in order to help an OP. Considerate responses may be perceived as more helpful and supportive to a help-seeker than a simple one-line matched responses like that in the example above.

\section{Unhelpfulness within Matches}

There were multiple types of responses that provided matches based on how they were coded, but were actually unhelpful or even harmful to help-seekers. However, these were not accounted for through the stress-buffering model framework. The first instance of this was through bad advice. Just because advice was provided does not necessarily mean that it was good advice. Regardless of the quality or relevancy of the advice, if it was provided, it was analyzed as a match for informational support. Therefore, if matches were made, the bad advice was grouped into informational support and considered helpful in buffering stress. The next example will show that bad advice can be dangerous. Providing suicidal individuals with bad advice is one facet of informal social support online that is concerning. Taking action based on poorly formulated advice could prove to have very harmful outcomes for these stigmatized individuals who have few other resources to turn to in an event of a situation going awry. This example follows in response to the same thread post in Example 1 above:

Cherub71: ... maybe you should consider getting yourself expelled. It can't be hard to do in a religious school. Your parents might be pretty upset, but not as horrified as they would be if they found your dead body. I'm serious. Shake things up by staying alive 
Although changing schools could be a good solution to the problem of being in an intolerant learning environment, purposely getting expelled could have many unintended consequences for this young OP. For example, having expulsion on their record could ruin their future opportunities, strain their relationship with their parents, and even risk their concealed minority gender identity being exposed through the process. Another example of bad advice providing a match for informational support was to consider prayer. The OP validates the response as unhelpful.

CockySir: ... have you considered prayer?...

OP: ...Praying and going to church has done nothing for me. I've prayed for acceptance, for bad thoughts of self-harm to be gone, for the real friends I have in my life, for my family not kicking me out permanently, but it has never helped me. I do believe in God but sometimes I don't think he is there for me. I also know I won't be under their roof forever and when I graduate can live the way I want without the fear of getting kicked out of my own house. Thanks for the advice though $<3$

In addition to bad advice, condemning comments were coded as a form of reappraisal because they function as a way of persuading the suicidal individual to think differently about suicide or their situation. These negative comments were sometimes considered a match for emotional support. For example, condemning was used by some responders as a means to express their own opinion about suicide as a selfish or cowardice act, specifically because it transfers the pain from the individual to their loved ones, or because "others have it worse". This tactic could possibly change someone's mind, but the negative connotations and name calling that was often involved brought unnecessary negatively to dire situations. When someone is experiencing suicidal ideations, it is risky to put them down as a response to help-seeking, especially if they are 
experiencing emotional losses and decreased self-esteem. Potential suicide is not a situation in which to be so harshly opinionated. Not once did a condemning comment receive a positive response or validation that it was helpful. In fact, it often created instances of responders monitoring and regulating others observed through disagreeing, disapproving, and criticizing comments towards those responders by other responders. Condemning comments are another facet of interaction that is lost through the matching model.

Lastly, irrelevant and off the wall comments did not necessarily skew the matching results, because they were not coded as functioning support buffer mechanisms, but their observation is also lost through the matching analysis of the stress-buffering model. These comments were not helpful in offering support because they did not address the OPs' needs.

\section{Virtual Environment Impacting Interaction}

The virtual setting of the interactions and how it may have affected social support interactions should also be considered. Not being in physical proximity to someone certainly inhibited the amount one can actually offer support in some cases. For example, the specificity of an OP's situation or need sometimes resulted in more difficulty for responders to meet their needs. An OP having more specific needs resulted in matches depending on more indirect support rather than directly meeting the OP's needs. One specific issue that occurred frequently was that of individuals wanting acceptance from their families. This problem is not easily alleviated or directly resolved by distant strangers offering companionship. Responders cannot do anything to change the way 
their parents view sexual minority identities, as they are often rooted in one's belief system. The responders do not know the OP's family, nor are they near them physically to intervene. The only way to address this need for love and acceptance is to offer it to them personally through social companionship or esteem support. However, this may only help temporarily as the OP will continue dealing with the family rejection, especially if they still live with their families. A match may be provided, but it does not actually help or change the OP's situation at home

By assessing these online interactions through dichotomous options, matched or unmatched support to needs, and buffer in stress, both the researcher and the responders must rely on the OP's post to decide what the needs are in order to meet them. Therefore, the responses that were provided to an OP depended on the manner in which an OP expressed and conveyed their problems and ideations. Some are more direct than others, and some far more detailed. Posts that were direct, detailed, and specific in their requests for support resulted in better matched responses. If an OP does not give enough information about their feelings or situation, it can be difficult to decipher the need that should be provided. Conversely, other OPs vent in great length and provide unnecessary detail and made it difficult to read and decipher their needs. This oversharing can overwhelm or confuse the responders to where they are unsure of what the point of the post is. Disclosing more detail in later comments led to additional confusion and an array of responses that only replied to the original post. Therefore, it is important for helpseekers to accurately convey their situations and needs in their initial posts. 
The emphasis placed on certain points of an OP's post naturally dictated the focus of responses. Responses generally focused on helping two different aspects of the OP's post: the suicidal ideations, or the root problems or situations causing the ideations. Sometimes both were addressed, but sometimes only one or the other were. The level of detail provided for each aspect also influenced which was addressed by responders. Some gave more detail about the issues causing them to feel hopeless and suicidal, while others only communicated that they wanted to end their lives without explaining any reasons why. Emotional support was used most often used in response to a focus on suicidal ideations, especially when they had to do with low self-esteem or feelings of being unlovable. Conversely, informational support, such as advice, was used more when the situation or root issue as emphasized. In addition, responder focus was turned to supporting the OP's ideations by default when there was not enough detail or information given about the root situation to offer solutions to.

Furthermore, the title of a post also influenced the types and amounts of responses that were provided. Posts with titles directly expressing suicidal ideations garnered more attention than those that were indirect. For example, a post titled "Having Suicidal Thoughts" received 33 comments, whereas a post titled simple "Help" only received 8 responses.

\section{EMERGED THEMES}

As a result of the issues encountered through the matching analysis, other themes were observed in these threads that were lost within the binary matching results. These themes included community, awareness, and challenged assumptions. 


\section{Community}

The first theme represents observations that provided support to conclude that LGBTchat.net serves as a medium for community building for its users. Side conversations between responders, frequent responders, and returning OPs points to this conclusion. There were two different types of side conversations found in this theme: discussions and community monitoring.

Opinions about advice and other relevant thread topics often led to side conversations between responders, rather than focusing on supporting the OP. In addition to disagreements over support responses, side conversations also included other responders disclosing ideations or personal situations, which were coded as social comparisons. This resulted in other responders replying to their comments rather than to the OP's original post. The following example displays a tangent discussion about selfharm alternatives on a thread:

OP: ...I sing to myself as relief so I don't cut like I used to.

Faded: I used to cut as well but I would always regret it after because of the pain. THE PAIN!!! It also leaves horrible scars. I still have scars on my wrists and knee. I try not to cut when I'm upset because I know I will regret it.

Beautiful_Dawn: An alternative to cutting is getting rubber bands that fit snug around your wrist, and when you want to cut just snap the band. It may leave a welt, but it does the job.

Faded: I've heard that that is good as well. I've tried it before and it's great if you want to hurt yourself but don't want a permanent scar. Also, the pain doesn't last as long as if you were to cut yourself.

BleedingHeart: I tried that, but rubber band cut me, so instead I use sharpies. The tip of the marker scratches a bit, but doesn't harm you and leaves marks behind. They aren't permanent and they're only there until it washes off. 
Community monitoring, on the other hand, occurred mostly in response to

condemning comments from other responders. These responses were concerned with how the OP would internalize such a negative response. Here is an example of this regulating behavior:

OP: I am stressed over who I am versus who I want to be. I'm over the guilt, frustrations, and pressures of being gay. I think more of death than I think of actually living. I know it is something you are born with, but I just can't live with it. I just want to be free of my homosexuality. My parents know and don't have a problem with my sexuality, but I still want to leave this life more than I want to be here. I don't know how long I can go on.

Conspirtor001: So you want to die...okay...what would be the result? Some will cry, some will be sad, some will miss you. You will regret it after. You're being a pussy by letting your sexuality define you. I have no friends and my dad considers me a failure deep down and I live in a homophobic country. Do you think you're the only one going through this? Get a life. You should be proud to be gay. You get to play games and have an upgraded best friend as a boyfriend. You want to miss out on that?

MysteriousSoul: Telling someone they are a pussy or that they've got it easy will not help get your point across or help them in any way...

This regulating response was followed by an apology by Conspritor001, proving the monitoring to be effective in keeping other responder messages appropriate. It also serves as evidence that responders educate others on how to better support a help-seeker. Later in the same thread is an example of how the apologetic responder disclosed their own problems with depression and resulted in side conversations that take the focus off of the OP:

Conspiritor001: I'm sorry for what I said at the time, it was mean and I was in a bad mood and feeling depressed...sorry.

MysteriousSoul: I'm sorry to hear that, but the fact that you have a positive outlook is great $:-$ I mean it! I just take these situations very seriously. Life can suck but there are still lots of reasons to hold on for tomorrow. I can promise that it will get 
better, not sure of when, but eventually life will be what you hope it will. I wish you both happiness.

Conspiritor001: I hope so, I keep thinking about the quote "Life is like an arrow, if it's dragging you down be prepared to get launched into something good." Still dreaming of coming to the U.S. three years later... Don't be sorry.. It was out of line for me to talk like that and being sad is not an excuse. It's more than ok for you to take this seriously... It shows that you care $;$

MysteriousSoul: Where are you located? If you come to the U.S., I wouldn't recommend the southern states. You should come to Canada, same sex marriage has been legal for a decade and Ontario's Premier is a lesbian. Anyway, message me if either of you want to talk! This is starting to get off topic.

Conpsiritor001: I live in Pakistan, so it will be hard to get a permanent visa there and I want to resettle somewhere permanently... I'm not sure Canada is a good choice because I want to enjoy my life as a teenager, and the US seems more designed for teens, like it's more entertaining.

Insane: How is the US designed for teenagers? Teens live all over the world. Really? It's just like any other country..

MysteriousSoul: I find them to be very similar, just slightly different people, but because they are also both large everything varies according to provinces and states. Canada has less crime overall and free health care! But that also means higher taxes. But I'm pretty biased and there's probably lots of things the US does better.

These forms of side conversation support the assertion made in other parts of this discussion that responders truly care about all members of the LGBTchat.net community. The care shown towards others through the online comments promotes and community building feelings of belonging. It also reflects that this virtual community has elements of face-to-face interactions because comments do not always only focus on one person, similar to verbal conversations. People talk amongst themselves in group conversation, get off topic, and also argue and disagree. The observed monitoring also reinforced role-taking within the community, like would happen in real social groups. Role-taking was specifically seen in frequent responders, another indicator of community on this site. 


\section{Frequent Responders}

The second indicator of community was the presence of frequent responders. There were four top responders and 11 others who also gave support in multiple threads. The top frequent responders were Beautiful_Dawn, Cherub71, Faded, and Muffler. Beautiful_Dawn, Cherub71, and Muffler are older individuals who spend a considerable amount of time online and make efforts to offer support to others and keep the forum a positive space.

Beautiful_Dawn, a 43 year old male-to-female transgender individual, was the top responder and provided 30 total comments across 20 of the sample threads and sent 3,409 individual messages within the forum. She was able to offer guidance and support from her personal experiences with suicidal ideations and transgender issues and a large amount of her responses provided matches.

Cherub71, who refers to himself as "the old guy," provided 17 comments across 12 threads, and sent 2,232 personal messages since being a member of the forum. He was observed commenting in many of the same threads as Beautiful_Dawn, and expressed great concern for suicidal individuals. He took on fatherly role in the forum and was commonly seen offering support to younger suicidal individuals.

Muffler, also an older male, provided 15 comments across 6 different threads. He claims in his bio that he wishes to keep the forum a good place for LGBTQ folks and sent 637 direct messages. Though his messages were always positive, ironically, he makes up many of the irrelevant and random, off-the-wall comments discussed in this chapter. 
Lastly, Faded, is only 15 years old, but also finds helping others who are suicidal important. His efforts resulted in 19 comments across 16 different threads. This young male often offered support backed by his own personal experience with depression and suicidal ideations.

These frequent responders are genuinely concerned about the wellbeing of the OP's as well as the outcomes of their situations. This concern was demonstrated when responders came back to a post to check on an OP after not receiving anymore responses from them. Cherub71 provided an example of this concern when he brought up an OP from prior threads whose suicidal ideations were very serious. The older post was referred to by Cherub71 because the OP had likewise not updated the forum on their situation after disclosing that they had a plan for suicide. Here is the somewhat condemning message made out of concerned frustration over the OP posting about killing them self and not responding to comments afterwards:

Cherub71: You know I think it's really messed up to announce that you are going to kill yourself here and then stop replying. What is the point in telling us if we can't do anything about it except for tell you reasons why it's bad and then keep wondering if they're still alive or not. Does anyone remember this? -inserts link to thread-

I'm still so worried about Oliv3r... did he ever get help or tell his mother? Is in the hospital? I'm not sure we will ever know. I messaged him to try checking in. Maybe he's doing better but afraid to come back to the forum because he might be embarrassed. I'm hoping for the best, but it makes me sick to my stomach thinking about it.

$@$ OP, if you come back and read this, please let us know. We will be so happy to know you are ok and won't think anything bad.

This example illustrates the investment frequent responders have in the individuals they help support in the forum. The frequent responders in these threads play a very important role in the online community because of their investment. They seemed to be online often 
enough to monitor threads that were concerning and involved at-risk members. For example, one of the guardian-like frequent responders, Beautiful_Dawn, was recognized for her role as a frequent supporter by others. This occurred through esteem support responses provided to her on her own support-seeking post. In said post, she vented about her difficult life experiences with being male-to-female transgender that made her feel suicidal and her continued feelings of unhappiness and hopelessness. Many of the responses to her post expressed bewilderment because her constant support and positivity towards others who need it in the forum made it surprising that she had experienced such harsh life conditions. Here is an example of Cherub71 reassuring her that others recognize her worth in the forum:

Cherub71: We all notice how helpful, supportive, and positive you are to others here in this forum. Every time I see a post of someone struggling, I ALWAYS see comments form you showing support and love. You are so important to all of us here and I can't imagine anyone NOT loving you.

Many other responses to this post concurred with Cherub71 in recognizing her support efforts in the forum. The availability and care of frequent responders reinforces feelings of community belonging and predictability for receiving support.

\section{Returning OPS}

The last indicator for the theme of community is the occurrence of OP's returning to the forum for more support. There were four individuals who turned to the forum for support more than once. This indicates that help-seeking individuals are finding the support they need the forum the first time, and found the social support helpful enough to turn to it again. The responders are reliable in offering support, which provides a true sense of community for these individuals. 
A supporting indication of LGBTchat.net serving as a true community, which was not discussed in the findings, is the diversity of individuals within it and the references made to other members. Forum members range in occupation, skill and expertise in addition to demographic backgrounds. Their varying backgrounds provide a rich source of information based on personal experience. For example, one responder referred an OP to speak to another community member who is a transgender lifeline counselor. Like the frequent responders, many forum members visit the site frequently enough to become familiar with other members. This familiarity with other members demonstrates that interactions in this community go beyond those seen in the collected threads. Another responder used their expertise as a manager of a live-in treatment facility to offer advice to a gay autistic individual who was experiencing institutional discrimination and abuse. The responder provided information about who the OP could contact in order to help their situation and offered alternative options they might consider. This diverse wealth of knowledge and expertise within the forum reflects that of a real life community as well as supports the assertion of LGBTchat.net having potential to continue providing social support to its members, especially those who are suicidal.

\section{Awareness}

Another important and interesting theme that emerged from these threads that supports the conclusion that stress-buffering is occurring through appropriate social support is the responders' awareness of suicide, mental health, and their limitations in offering support through a virtual setting. These observations could be found in response to other negative responses, such as condemning ones and those involved with 
community monitoring. This awareness allows members to keep one another in check and assure that at-risk individuals are receiving the support they need.

Suicide

There was evidence of responder awareness of suicide and how to handle a situation in which an individual is help-seeking for their ideations. Here is one example of blatantly stated awareness of the LGBTQ community as an at-risk group for suicide:

Holly_626:....But I never acted on my thoughts of suicide and because I didn't kill myself, I can now help other troubled teens in our community, since our population has a high rate of suicide. I attribute this to lack of conversation on the topic and lack of acceptance of us.

The underlined portion shows how the responder is aware of suicide being a problem within the larger LGBTQ community and their hypothesis as a reason why it is so. The next example is a result of a monitoring response to a condemning and unhelpful comment towards an OP that signifies awareness:

Faded: ...I'm assuming you live in a pretty nice country, am I right? One with access to water with high income? If that's the case then you shouldn't be thinking about suicide. You have roof over your head, food and water, and a chance to really live. You're going to throw that away just because of the idea that you're "supposed" to like women? Wow. So many people have it worse than you, why are you complaining?

MysteriousSoul: I totally disagree with the point you are trying to make. We don't know what his living situation is like and there's other things that affect our happiness and perceptions. What is a huge deal to me may not be to you.

Mental health problems are not something you can ignore. You can have the world at your disposal, but if you have anxiety, it can be hard to get out there and enjoy life. He is not suicidal because he feels sorry for himself because he's gay, it's a real problem caused by multiple things and are hard to overcome. You can't just put on a fake smile and act like you're ok all the time. You can't see the silver linings when you're depressed. 
In the underlined portion, MysteriousSoul is informing Faded as to why the OP may be considering suicide and that it is difficult to manage and see another way out. After Mysterious Soul stepped in, Faded ended up apologizing for his negativity.

MysteriousSoul was not only able to mitigate a situation based on their own awareness of suicide and mental health, but also educated another person about how to handle such a situation.

\section{Mental Health}

Awareness of mental health in general and how it should be treated or supported was also observed. This was observed through responses in which the responders acknowledge that professional support is needed and that they are limited in the support they are able to provide individuals who need counseling for mental health problems. Mental health professionals and social support researchers have been concerned about the information and kinds of support that isolated, at-risk individuals are receiving when they turn to informal sources like LGBTchat.net. Therefore, this observation is a positive finding because it shows that responders are not trying to treat individuals with serious issues, but rather encouraging them to seek professional resources. The following exemplifies responder awareness of their limitations to helping OPs with mental health issues:

Lorin: This situation sounds like it is emotionally deeply rooted and unfortunately I don't think that people in an online form would be able to affectively guide you through the healing process. 


\section{Limitations of Online Support}

The example above also indicates that responders are aware of the limitations they have in giving proper support to suicidal individuals due to being in an online space. The example used in the frequent responders section from Cherub71 also illustrates an awareness of the limitations to his ability to help the suicidal OP. Another frequent responder, PinkKisses43 agreed with Cherub71:

PinkKisses43: I totally agree... all we can do is try to persuade them from doing it... we can't do anything for them physically... its really terrible $:$

Responder awareness of the limitations to the extent in which they are able to offer support in the virtual setting was also recorded. This awareness is also reflected in the other points of awareness discussed. The other points of awareness discussed support this assertion because they know that online peer-to-peer social support is not sufficient in fully fixing the OP's problems and that further resources are needed. The advice given to seek therapy, and referrals to therapists and hotlines for those who were immediately suicidal also supports this conclusion.

\section{Challenged Assumptions}

In contrast to the observation of responders' awareness of the inadequacy of an informal online forum advising that OPs seek professional help, there was evidence of help-seekers turning to the forum when these traditional or professional help resources failed them. These cases were interesting because they disrupted the assumption that this population and behavior of online help-seeking is due in part to decreased access to these resources and are therefore, turning to alternate sources. Evidence that some OPs had previously called hotlines, seen therapists, or reached out to other sources for help, such 
as school counselors was found. Here is an example of a response indicating that an OP

had utilized a hotline before turning the forum:

OP: I am not allowed to wear pants at my school because I go to a religious school with uniforms and it sucks. I have called the kids helpline before and they have therapists to talk with on site, but I need to let my parents know to take me to therapy.

Another OP disclosed that they had seen a therapist pro bono, but were no longer:

OP: You don't even know me so why are you helping me? Not even my "friends" were helpful... My psychologist even blocked me, the bitch, I guess she was mad I didn't pay her but she volunteered to help me pro bono. But I guess she wasn't sincere.

These examples indicate that this online community provides something that professional services are not: a sense of belonging. Where professional services are certainly helpful in teaching LGBTQ individuals to cope with their unique issues, they cannot cross the professional relationship boundary. They cannot provide friendships or the social interaction necessary in impacting over-all happiness and sense of belonging that is important for promoting positive mental health. Being able to relate to others helps one feel less alone. It helps to be able to talk to someone with firsthand experience rather than someone who is getting paid to support you.

\section{CRITIQUE OF THE THEORY}

The issues encountered using the stress-buffering model and the other themes that emerged from the data suggest that using a simple matching model is insufficient for fully analyzing the social support interactions among these unique and intersectional individuals. Human social behavior, especially online, is far more complex than a dichotomous matching system can decipher. The simple matching methodology hinders 
validation and does not allow meaningful results to be gathered when applied to social support for LGBTQ specific issues. A more intersectional and flexible lens is needed for this context.

The stress-buffering model is too vague and weak to be used for a qualitative content analysis of the phenomenon investigated in this study. A match between needs and support should not be the only way of deciphering helpfulness of support or buffer in stress. The issues encountered when applying the model qualitatively suggest that a serious reframing of the stress-buffering model should be considered when applying it to direct observations of social support behaviors. The variability among human behavior, identities, and interactions should be heavily considered in a reconceptualization of how social support buffers stress and the specific situations in which a matching method may actually apply well. 


\section{Chapter 7. Conclusion}

This research investigated an important phenomena of help-seeking for suicidal ideations in stigmatized and isolated individuals. It can be concluded that the majority of social support responses provided to suicidal individuals in LGBTchat.net are helpful in meeting their needs and therefore, provides evidence for a buffer in stress and even helping avoid suicide attempts. This site has potential to be a medium for future helpseekers needing social support to turn to due to the evidence of needs-support matching. The results from both the matching analysis conceptualized by the stress-buffering model and the emerged themes show that the support provided in this online forum are positive and helpful, especially for providing a sense of belonging and community. The findings and analysis have wider implications for not only mental health professionals or suicide prevention planning services and departments, but also for the broader LGBTQ population and their social circles.

Through the emerged themes, it was found that within the diverse group of members in this forum, many are aware of the sensitive nature of suicidal ideations and mental health issues. However, this research also exposed some of the limitations of social support in virtual settings and the types of issues that can affectively be helped online. For example, family rejection cannot be solved or directly helped through online social support. This common issue points to the need for more local LGBTQ resources that can help those who are rejected by their families as well as provide a physical resource and community for social support. 
Moreover, the finding that some individuals in the forum are turning to this site in spite of having already sought professional services indicates that LGBTchat.net serves as a safe outlet for community building expression, confiding in similar others. It also demonstrates that formal services are not filling all of this population's needs, especially the need for acceptance and belonging. Professional services should work to facilitate good community connections with local LGBTQ resources to refer their patients to in order to supplement their treatment. Therapists and counselors should consider making this a vital component of treatment for LGBTQ patients, and possibly consider incorporating online support groups as well when appropriate. Prevention efforts should also take this finding into consideration and make more efforts to reach isolated individuals in virtual spaces like that of LGBTchat.net.

In addition to concerns for the well-being of these individuals and others who are suicidal, this research also has implications for help-seekers in general. Online, or off, being specific and direct in communicating needs ensures that the best support possible will be provided, especially in online settings where responses are dictated by the way in which needs are conveyed through written communication.

Beyond the wider implications of this research, insight about the applicability of the stress-buffering model to qualitative research is also provided. Through applying this framework to online observations of social support, it was concluded that human behavior is too complex to analyze using a simple matching model for online interactions with written communication. The model may apply better to ethnographic or interview methods where more details, such as perceptions of support, health outcomes, or 
validation that a suicidal individual avoided an attempt as a result of the support, can be gained.

Future research should consider applying this theory to these other forms of qualitative methods to test its applicability. It would also be interesting to see it applied to other types of online forums such as issue-specific support groups to verify whether the poor applicability was due to the nature of online interactions, or if the unique experiences of LGBTQ individuals with suicidal ideations determined this conclusion. Deeper analysis of how buffer mechanisms function together should also be explored further. Lastly, efforts should be made to find a better method of analyzing social support responses for suicidal LGBTQ individuals with a more flexible and encompassing lens in order to more properly capture the intersectional variances that effect this population, their experiences, and the resulting support available to them. 


\section{REFERENCES}

Abramson, Lyn Y., Martin E. Seligman, and John D. Teasdale. 1978. "Learned Helplessness in Humans: Critique and Reformulation." Journal of Abnormal Psychology 87(1):49-74.

World Health Organization. 2017. "Suicide.” Retrieved November 7, 2016b (http://www.who.int/mediacentre/factsheets/fs398/en/).

Bambina, Antonina. 2007. Online Social Support: The Interplay of Social Networks and Computer-Mediated Communication. Youngstown, N.Y.: Cambria Press. Retrieved February 26, 2017 (http://search.ebscohost.com/login.aspx?direct=true \&scope=site $\& \mathrm{db}=\mathrm{nlebk} \& \mathrm{db}=$ nlabk\&AN=498731).

Bandura, Albert. 1986. Social Foundations of Thought and Action: A Social Cognitive Theory. NY: Prentice-Hall.

Barak, Azy. 2007. "Emotional Support and Suicide Prevention through the Internet: A Field Project Report." Computers in Human Behavior 23(2):971-84.

Bell, Roger A., Joseph B. Leroy, and Judith J. Stephenson. 1982. "Evaluating the Mediating Effects of Social Support upon Life Events and Depressive Symptoms." Journal of Community Psychology 10(4):325-40.

Berkman, L. F., L. Breslow, and D. Wingard. 1983. "Health Practices and Mortality Risk." Pp. 61-112 in Health and ways of living: the Alameda County study. New York, NY: Oxford University Press. Retrieved February 26, 2017 (http://www.popline.org/node/413708).

Blosnich, John and Robert Bossarte. 2012. "Drivers of Disparity: Differences in Socially Based Risk Factors of Self-Injurious and Suicidal Behaviors Among Sexual Minority College Students." Journal of American College Health 60(2):141-49.

Blosnich, John R., Robert M. Bossarte, and Vincent M. B. Silenzio. 2012. "Suicidal Ideation Among Sexual Minority Veterans: Results From the 2005-2010 Massachusetts Behavioral Risk Factor Surveillance Survey." American Journal of Public Health 102(S1):S44-47.

Blosnich, John R., Laura J. Nasuti, Vickie M. Mays, and Susan D. Cochran. 2016. "Suicidality and Sexual Orientation: Characteristics of Symptom Severity, Disclosure, and Timing across the Life Course." American Journal of Orthopsychiatry 86(1):69-78. 
Braithwaite, Dawn O., Vincent R. Waldron, and Jerry Finn. 1999. "Communication of Social Support in Computer-Mediated Groups for People With Disabilities." Health Communication 11(2):123-51.

Breault, K. D. 1986. "Suicide in America: A Test of Durkheim's Theory of Religious and Family Integration, 1933-1980.” American Journal of Sociology 92(3):628-56.

Brooks, V. R. 1981. Minority Stress and Lesbian Women. Free Press.

Brownell, Arlene and Sally Ann Shumaker. 1984. "Social Support: An Introduction to a Complex Phenomenon." Journal of Social Issues 40(4):1-9.

Burleson, B. R. 1982. "The Development of Comforting Communication Skills in Childhood and Adolescence." Child Development 53(6):1578-88.

Burleson, B. R. 1987. "Cognitive Complexity." Pp. 305-349 in Personality and interpersonal communication. Newbury Park, CA: Sage.

Caplan, R. D. 1979. "Social Support, Person-Environment Fit, and Coping." Pp. 89-137 in Mental health and the economy.

Cassel, John. 1976. "The Contribution of the Social Environment to Host Resistance." American Journal of Epidemiology 104(2):107-23.

Centers for Disease Control and Prevention (CDC). 2013. "Web-Based Injury Statistics Query and Reporting System (WISQARS)." National Center for Injury

Prevention and Control, CDC (Producer). Retrieved May 3, 2017

(https://www.cdc.gov/injury/wisqars/).

Chong, Eddie S. K., Yin Zhang, Winnie W. S. Mak, and Ingrid H. Y. Pang. 2015. "Social Media as Social Capital of LGB Individuals in Hong Kong: Its Relations with Group Membership, Stigma, and Mental Well-Being." American Journal of Community Psychology 55(1-2):228-38.

Cobb, Sidney. 1976. "Social Support as a Moderator of Life Stress." Psychosomatic Medicine Psychosomatic Medicine 38(5):300-314.

Cochran, Susan D., Vickie M. Mays, Margarita Alegria, Alexander N. Ortega, and David Takeuchi. 2007. "Mental Health and Substance Use Disorders among Latino and Asian American Lesbian, Gay, and Bisexual Adults." Journal of Consulting and Clinical Psychology 75(5):785-94.

Cohen, Carl I., Jeanne Teresi, and Douglas Holmes. 1987. "Social Networks and Mortality in an Inner-City Elderly Population." The International Journal of Aging and Human Development 24(4):257-69. 
Cohen, Sheldon and Garth McKay. 1984. "Social Support, Stress and the Buffering Hypothesis: A Theoretical Analysis." Handbook of Psychology and Health (4):253-67.

Cohen, Sheldon and Thomas A. Wills. 1985. "Stress, Social Support, and the Buffering Hypothesis." Psychological Bulletin 98(2):310-57.

Cooley, Charles Horton. 1902. "The Looking-Glass Self." Pp. 179-85 in Human Nature and the Social Order. New York: Scribner's.

Cummings, Jonathon N., Lee Sproull, and Sara B. Kiesler. 2002. "Beyond Hearing: Where the Real-World and Online Support Meet." Group Dynamics: Theory, Research, and Practice 6(1):78-88.

Cutrona, C. E. and J. A. Suhr. 1994. "Social Support Communication in the Context of Marriage: An Analysis of Couples' Supportive Interactions." in The Communication of Social Support: Messages, Interactions, Relationships, and Community. Newbury, CA: Sage.

Cutrona, Carolyn E. and Daniel W. Russell. 1990. "Type of Social Support and Specific Stress: Toward a Theory of Optimal Matching." ResearchGate. Retrieved November 27, 2016 (https://www.researchgate.net/publication/232560583_Type_of_social_support_a nd_specific_stress_Toward_a_theory_of_optimal_matching).

Cutrona, C. E. and J. A. Suhr. 1992. "Controllability of Stressful Events and Satisfaction with Spouse Support Behaviors." Communication Research 19(2):154-74.

Danigelis, Nick and Whitney Pope. 1979. "Durkheim's Theory of Suicide as Applied to the Family: A Empirical Test." Social Forces 57(4):1081-1106.

Durkheim, Émile. 1897. Le suicide: étude de sociologie. F. Alcan.

Durkheim, Émile. 1951. Suicide, a Study in Sociology. Glencoe, Ill.: Free Press.

Durso, Laura E. and Gary J. Gates. 2012. "Serving Our Youth: Findings from a National Survey of Services Providers Working with Lesbian, Gay, Bisexual and Transgender Youth Who Are Homeless or At Risk of Becoming Homeless." eScholarship. Retrieved February 23, 2017 (http://escholarship.org/uc/item/80x75033).

Elo S and Kyngäs H. 2008. "The Qualitative Content Analysis Process." Journal of Advanced Nursing 62(1):107-15. 
Falk, Ian and Sue Kilpatrick. 2000. "What Is Social Capital? A Study of Interaction in a Rural Community.” Sociologia Ruralis 40(1):87-110.

Finn, J. and T. Steele. 2010. "Online Self-Help/Mutual Aid Groups in Mental Health Practice.” Pp. 87-105 in Mental Health Self-Help, edited by L. D. Brown and S. Wituk. Springer New York. Retrieved October 10, 2016 (http://link.springer.com/chapter/10.1007/978-1-4419-6253-9_5).

Fitzpatrick, Scott J., Claire Hooker, and Ian Kerridge. 2014. "Suicidology as a Social Practice.” Social Epistemology Social Epistemology 29(3):303-22.

Friedman, Richard C. 1999. "Homosexuality, Psychopathology, and Suicidality." Archives of General Psychiatry 56(10):887-88.

Frost, David M. and Ilan H. Meyer. 2012. "Measuring Community Connectedness among Diverse Sexual Minority Populations.” Journal of Sex Research 49(1):36-49.

Fukkink, Ruben. 2011. "Peer Counseling in an Online Chat Service: A Content Analysis of Social Support." CyberPsychology, Behavior \& Social Networking 14(4):24751.

Funch, Donna P. and James Marshall. 1983. "The Role of Stress, Social Support and Age in Survival from Breast Cancer." Journal of Psychosomatic Research 27(1):7783.

Gilat, Itzhak and Golan Shahar. 2009. "Suicide Prevention by Online Support Groups: An Action Theory-Based Model of Emotional First Aid.” Archives of Suicide Research 13(1):52-63.

Gottlieb, Benjamin H., Lynn Underwood Gordon, Sheldon Cohen, and Fetzer Institute. 2000. Social Support Measurement and Intervention : A Guide for Health and Social Scientists. Oxford: Oxford University Press. Retrieved February 25, 2017 (http://search.ebscohost.com/login.aspx?direct=true \&db=nlebk\&AN=277633\&sit e=ehost-live).

Graaf, Ron de, Theo G. M. Sandfort, and Margreet ten Have. 2006. "Suicidality and Sexual Orientation: Differences Between Men and Women in a General Population-Based Sample From The Netherlands." Archives of Sexual Behavior 35(3):253-62.

Granovetter, Mark S. 1973. “The Strength of Weak Ties.” American Journal of Sociology 78(6):1360-80.

Grant, Jaime M., Lisa A. Mottet, and Justin Tanis. 2011. Injustice at Every Turn: A Report of the National Transgender Discrimination Survey. Washington: National 
Center for Transgender Equality and National Gay and Lesbian Task Force.

Retrieved February 23, 2017

(http://www.thetaskforce.org/static_html/downloads/reports/reports/ntds_full.pdf)

Grossman, Arnold H. and Anthony R. D'Augelli. 2007. "Transgender Youth and LifeThreatening Behaviors." Suicide and Life-Threatening Behavior 37(5):527-37.

Haas, Ann P., Philip L. Rodgers, and Jody L. Herman. 2014. Suicide Attempts among Transgender and Gender Non-Conforming Adults: Findings of the National Transgender Discriminiation Survey. American Foundation for Suicide Prevenion and the Williams Institute. Retrieved February 24, 2017 (http://williamsinstitute.law.ucla.edu/wp-content/uploads/AFSP-WilliamsSuicide-Report-Final.pdf).

Heller, K. 1979. "The Effects of Social Support: Prevention and Treatment Implications." Pp. 353-82 in Maximizing treatment gains: Transfer enhancement in psychotherapy. Academic Press.

Herring, Susan C. 2009. "Web Content Analysis: Expanding the Paradigm.” Pp. 233-49 in International Handbook of Internet Research, edited by J. Hunsinger, L. Klastrup, and M. Allen. Springer Netherlands. Retrieved September 30, 2016 (http://link.springer.com/chapter/10.1007/978-1-4020-9789-8_14).

Hillier, Lynne and Lyn Harrison. 2007. "Building Realities Less Limited Than Their Own: Young People Practising Same-Sex Attraction on the Internet." Sexualities 10(1):82-100.

Horwitz, A. V. 1984. “Therapy and Social Solidarity.” Pp. 211-44 in Towards a General Theory of Social Control: Fundamentals, vol. 1. Academic Press, Inc.

House, James S. 1981. Work Stress and Social Support. Addison-Wesley Pub. Co. Retrieved November 4, 2016 (http://agris.fao.org/agrissearch/search.do?recordID=US201300364231).

Hsieh, Hsiu-Fang and Sarah E. Shannon. 2005. "Three Approaches to Qualitative Content Analysis." Qualitative Health Research 15(9):1277-88.

Hull, Shawnika J., Eulalia P. Abril, Dhavan V. Shah, Mina Choi, Ming-Yuan Chih, Sojung Claire Kim, Kang Namkoong, Fiona McTavish, and David H. Gustafson. 2016. "Self-Determination Theory and Computer-Mediated Support: Modeling Effects on Breast Cancer Patient's Quality-of-Life." Health Communication 31(10):1205-14. 
Kitzinger, Celia. 2005. "Heteronormativity in Action: Reproducing the Heterosexual Nuclear Family in After-Hours Medical Calls." Social Problems 52(4):477-98.

Knizek, Birthe Loa and Heidi Hjelmeland. 2007. "A Theoretical Model for Interpreting Suicidal Behaviour as Communication.” Theory \& Psychology 17(5):697-720.

Kposowa, Augustine J. 2000. "Marital Status and Suicide in the National Longitudinal Mortality Study.” Journal of Epidemiology \& Community Health 54(4):254-61.

Landman-Peeters, Karlien M. C., Catharina A. Hartman, Gieta van der Pompe, Johan A. den Boer, Ruud B. Minderaa, Johan Ormel.. 2005. "Gender Differences in the Relation between Social Support, Problems in Parent-Offspring Communication, and Depression and Anxiety." Social Science \& Medicine 60(11):2549-59.

Lazarus, Richard S. 1966. Psychological Stress and the Coping Process. New York, NY, US: McGraw-Hill.

Lazarus, Richard S. and Susan Folkman. 1984. Stress, Appraisal, and Coping. Springer Publishing Company.

Leenars, Antoon A. 2002. "In Defense of the Idiographic Approach: Studies of Suicide Notes and Personal Documents." Archives of Suicide Research 6(1):19-30.

Lin, Nan, Walter M. Ensel, Ronald S. Simeone, and Wen Kuo. 1979. "Social Support, Stressful Life Events, and Illness: A Model and an Empirical Test." Journal of Health and Social Behavior 20(2):108-19.

Lynsen, Ann. 2014. "Populations at Risk for Suicide.” Retrieved November 27, 2016 (http://www.samhsa.gov/suicide-prevention/at-risk-populations).

Maimon, David and Danielle C. Kuhl. 2008. "Social Control and Youth Suicidality: Situating Durkheim's Ideas in a Multilevel Framework." American Sociological Review 73(6):921-43.

Maris, Ronald W. 1981. Pathways to Suicide: A Survey of Self-Destructive Behaviors. John Hopkins University Press.

Marshal, Michael P., Laura J. Dietz, Mark S. Friedman, Ron Stall, Helen A. Smith, James McGinley, Brian C Thoma, Pamela J. Murray, Anthony R. D'Augelli, David A. Brent. 2011. "Suicidality and Depression Disparities Between Sexual Minority and Heterosexual Youth: A Meta-Analytic Review." Journal of Adolescent Health 49(2):115-23. 
McKenna, Katelyn Y. A. and John A. Bargh. 2000. "Plan 9 From Cyberspace: The Implications of the Internet for Personality and Social Psychology." Personality and Social Psychology Review 4(1):57-75.

Mead, George H. 1935. Mind, Self, and Society. Chicago: University of Chicago Press.

Meyer, Ilan H. 1995. "Minority Stress and Mental Health in Gay Men.” Journal of Health and Social Behavior 36(1):38-56.

Miller, John K. and Kenneth J. Gergen. 1998. "Life on the Line: The Therapeutic Potentials of Computer Mediated Conversation." Journal of Marital and Family Therapy 24(2):189-202.

Miller, P. M. and J. G. Ingham. 1979. "Reflections on the Life Events to Illness Link with Some Preliminary Findings.” Pp. 313-36 in Stress and anxiety, vol. 6.

Movement Advancement Project. 2017. “Equality Maps.” Retrieved February 23, 2017 (http://www.lgbtmap.org/equality-maps/).

Naslund, J. A., K. A. Aschbrenner, L. A. Marsch, and S. J. Bartels. 2016. "The Future of Mental Health Care: Peer-Topeer Support and Social Media." Epidemiology and Psychiatric Sciences 25(2):113-22.

Obergefell v. Hodges, 576 U.S. (2015).

Orth-Gomér, Kristina. 1994. "International Epidemiological Evidence for a Relationship between Social Support and Cardiovascular Disease.” Pp. 97-117 in Social Support and Cardiovascular Disease, The Springer Series in Behavioral Psychophysiology and Medicine, edited by S. A. Shumaker and S. M. Czajkowski. Springer US. Retrieved February 26, 2017 (http://link.springer.com/chapter/10.1007/978-1-4899-2572-5_5).

Owen, Gareth, Judith Belam, Helen Lambert, Jenny Donovan, Frances Rapport, Christabel Owens. 2012. "Suicide Communication Events: Lay Interpretation of the Communication of Suicidal Ideation and Intent." Social Science \& Medicine 75(2):419-28.

Park, Robert E. and Ernest W. Burgess. 1926. The City. University of Chicago Press.

Pearlin, Leonard I. and Carmi Schooler. 1978. "The Structure of Coping." Journal of Health and Social Behavior 19(1):2-21.

Pfeil, Ulrike, Knut Svangstu, Chee Siang Ang, and Panayiotis Zaphiris. 2011. "Social Roles in an Online Support Community for Older People." International Journal of Human-Computer Interaction 27(4):323-47. 
Pfeil, Ulrike and Panayiotis Zaphiris. 2009. "Applying Qualitative Content Analysis to Study Online Support Communities." Universal Access in the Information Society 9(1):1-16.

Plöderl, Martin, Clements Fartacek, Reinhold Faracek, Karl Kralovec, Richard Ramsay, Pierre Tremblay, Eric-Jan Wagenmakers. 2013. "Suicide Risk and Sexual Orientation: A Critical Review." Archives of Sexual Behavior 42(5):715-27.

Ravitz, Jessica. 2016. "Calls to Crisis, Suicide Prevention Hotlines Surge Post-Election.” CNN. Retrieved February 24, 2017

(http://www.cnn.com/2016/11/11/health/election-crisis-suicide-preventionhotlines/index.html).

Reber, Arthur S. 1995. The Penguin Dictionary of Psychology, 2nd Ed. New York, NY, US: Penguin Press.

Russell, Stephen T. and Kara Joyner. 2001. “Adolescent Sexual Orientation and Suicide Risk: Evidence From a National Study." American Journal of Public Health 91(8):1276-81.

Ryan, Caitlin. 2009. Helping Families Support Their Lesbian, Gay, Bisexual, and Transgender (LGBT) Children. Washington, DC: National Center for Cultural Competence, Georgetown University Center for Child and Human Development. Retrieved February 27, 2017 (https://nccc.georgetown.edu/documents/LGBT_Brief.pdf).

Sanders, Douglas. 1996. "Getting Lesbian and Gay Issues on the International Human Rights Agenda.” Human Rights Quarterly 18(1):67-106.

Schilt, Kristen and Laurel Westbrook. 2009. "Doing Gender, Doing Heteronormativity: 'Gender Normals,' Transgender People, and the Social Maintenance of Heterosexuality." Gender \& Society 23(4):440-64.

Sells, S. B. 1970. "On the Nature of Stress.” P. 139 in Social and psychological factors in stress, 134.

Silenzio, Vincent M. B., Juan B. Pena, Paul R. Duberstein, Julie Cerel, and Kerry L. Knox. 2007. "Sexual Orientation and Risk Factors for Suicidal Ideation and Suicide Attempts Among Adolescents and Young Adults." American Journal of Public Health 97(11):2017-19.

Silverman, Morton M. 2006. "The Language of Suicidology.” Suicide \& LifeThreatening Behavior 36(5):519-32. 
Spears, Russel and Martin Lea. 1994. "Panacea or Panopticon?: The Hidden Power in Computer-Mediated Communication.” Communication Research 21(4):427-59.

Thomas, W. I. and F. Znaniecki. 1920. The Polish Peasant in Europe and America: Disorganization and Reorganization in Poland. R. Badger.

Tong, Stephanie Tom, Daria Heinemann-LaFave, Jehoon Jeon, Renata Kolodziej-Smith, and Nathaniel Warshay. 2013. "The Use of Pro-Ana Blogs for Online Social Support.” Eating Disorders 21(5):408-22.

United Nations, General Assembly. 2015. Discrimination and Violence against Individuals Based on Their Sexual Orientation and Gender Identity. United Nations.

Wallace, Jean E. 2005. “Job Stress, Depression and Work-to-Family Conflict: A Test of the Strain and Buffer Hypotheses." Relations Industrielles / Industrial Relations 60(3):510-39.

Walther, Joseph B. and S. Boyd. 2002. "Attraction to Computer-Mediated Social Support." Communication Technology and Society: Audience Adoption and Uses 153-88.

Wasserman, Ira M. 1984. "A Longitudinal Analysis of the Linkage between Suicide, Unemployment, and Marital Dissolution." Journal of Marriage and Family 46(4):853-59.

Weare, Christopher and Wan-Ying Lin. 2000. "Content Analysis of the World Wide Web: Opportunities and Challenges." Social Science Computer Review 18(3):272-92.

Weinstein, Emily C., Robert L. Selman, Sarah Thomas, Jung-Eun Kim, Allison E. White, and Karthik Dinakar. 2016. "How to Cope With Digital Stress The Recommendations Adolescents Offer Their Peers Online." Journal of Adolescent Research 31(4):415-41.

Wellman, B. and M. Gulia. 1999. "The Network Basis of Social Support: A Network Is More than the Sum of Its Ties.” Pp. 83-118 in Networks in the global village.

White, Leroy and Bob Cant. 2003. "Social Networks, Social Support, Health and HIVPositive Gay Men.” Health \& Social Care in the Community 11(4):329-34.

Wichstrøm, Lars and Kristinn Hegna. 2003. "Sexual Orientation and Suicide Attempt: A Longitudinal Study of the General Norwegian Adolescent Population." Journal of Abnormal Psychology 112(1):144-51. 
Williams, Stacey L., Sheri L. Laduke, Kathleen A. Klik, and David W. Hutsell. 2016. "A Paradox of Support Seeking and Support Response among Gays and Lesbians." Personal Relationships 23(2):296-310.

Wills, Thomas A. 1981. "Downward Comparison Principles in Social Psychology." Psychological Bulletin 90(2):245-71.

World Health Organization. 2016. World Health Statistics 2016: Monitoring Health for the Sustainable Development Goals. Geneva, Switzerland. 